\title{
Advances in the understanding of hereditary ataxia \\ - implications for future patients
}

\begin{abstract}
Introduction: Hereditary ataxias are caused by mutations in a plethora of different genes. Advances in sequencing technologies have led to an exponential increase in novel gene discoveries, highlighted the genetic overlap with other neurological diseases and improved our understanding of genotype-phenotype relationships. Together, these developments allowed the identification of new therapeutic targets that are subsequently making their way into clinical trials.
\end{abstract}

Areas covered: This review focuses on the shared genetic characteristics and the latest insights into the molecular cause of the most prevalent hereditary ataxias. Furthermore, conventional genetic diagnosis and the gradual implementation of next-generation sequencing (NGS) approaches in clinical practice is discussed. Finally, the latest investigated disease-modifying therapeutic agents are reviewed. A literature search was performed in PubMed and the Cochrane Library. Additional information on previous and on-going trials was obtained from the ClinicalTrials.gov website.

Expert opinion: The implementation of NGS in clinical practice has led to an increase in detected sequence variants of unknown clinical significance. Determining their pathogenicity is an expensive and time-consuming process. However, misinterpretation of these variants can have far-reaching consequences for the patient and their relatives. In accordance with the progresses in genetics, there is a need for the simultaneous definition of novel biomarkers and functional assays that can assist in the interpretation of genetic tests. Moreover, the identification of biomarkers that are relevant to specific diseases has the potential to improve clinical trial design. 


\section{Article highlights}

- Hereditary ataxias are mono-genetic diseases that show genetic and clinical heterogeneity with marked phenotypical overlap.

- The most prevalent dominant, recessive and X-linked ataxias are due to a trinucleotide repeat expansion in their respective genes.

- Depending on the disease-causing gene, the length and configuration of these trinucleotide repeat expansions variably influences age of onset, intergenerational instability and phenotypic presentation.

- Advances in sequencing technologies, such as next-generation sequencing, have revolutionised the genetic landscape of ataxias and are increasingly implemented in clinical practice.

- Disease-modifying treatments target the genetic cause of the disease directly or focus on shared pathological downstream mechanisms. Biomarkers could prove useful in monitoring therapeutic response. 


\section{Introduction}

The term hereditary ataxia encompasses a clinically and genetically heterogeneous group of disorders. They share a progressive incoordination of motor activity affecting gait, extraocular movements and speech. ${ }^{1}$ Underlying these conditions is a well-described genetic association with autosomal dominant, autosomal recessive, X-linked or mitochondrial transmission. ${ }^{2}$ Even though marked variability in intra- and interfamilial phenotypical presentation were identified early in their description, and different genetic backgrounds suspected, the number of distinct genetic causes has only recently begun to be unravelled. ${ }^{3}$ The first milestones of gene discovery in hereditary ataxia were made in the early 1990s with the discovery of pathogenic repetitive trinucleotide repeat (TR) expansions within the ATXN1 gene in Spinocerebellar ataxia type 1, and the $F X N$ gene in Friedreich's ataxia (FRDA). ${ }^{4,5}$ Both causative genes were discovered by linkage analysis and subsequent Sanger sequencing.

In the last two decades, conventional sequencing techniques have gradually been replaced by next-generation sequencing (NGS). These new approaches are capable of reading huge amounts of genetic sequences in parallel. ${ }^{6}$ NGS has undoubtedly revolutionised the field of ataxia by broadening our knowledge about the phenotypic spectrum of known ataxia associated genes and exponentially increasing the number of novel gene discoveries (Figure 1) ${ }^{7,8}$ To date, over 40 different disease-causing gene loci have been mapped in autosomal dominant cerebellar ataxias (ADCA) (Table 1). These genetic loci have been labelled spinocerebellar ataxia (SCA) and numbered in chronological order of their discovery. The group of eight known episodic ataxias and Dentatorubral-pallidoluysian atrophy (DRPLA) are an exception to this nomenclature. In addition, an equally high number of causative genes has been identified in recessive ataxias (Table 2). However, their classification remains a challenge due to a lack of uniform nomenclature and the vast number of recessive neurological diseases presenting 
with symptoms of ataxia. This is reflected by the marked variability in disorders that are included to the group of hereditary recessive ataxias in literature. ${ }^{9}$ Although numerous, both dominant and recessive ataxias belong to the group of rare diseases. The average prevalence is 2.7 in 100,000 and 3.3 in 100,000, respectively. ${ }^{10}$ An awareness of the great variation in prevalence of distinctive ataxic disorders that exists in different ethnical groups and geographic regions may facilitate the choice of genetic tests in clinical practice.

The observed phenotypical overlap between hereditary ataxias is surprising considering the broad structural and functional differences in the disease-causing proteins. Physiological functions of disease-causing genes in SCAs include ion transport, deubiquitination, dephosphorylation and phosphorylation, transcriptional regulation and translational elongation. ${ }^{11}$ The nuclear gene $F X N$ that is mutated in FRDA encodes for a well-studied, ubiquitously expressed mitochondrial protein that is crucial for the biogenesis of iron-sulphur clusters and haem.,12 The literature on pathological downstream mechanisms is rapidly growing, however their individual contribution to neurodegeneration remains unclear. The fact that this genetic heterogeneity results in such a similar clinical picture drives the search for shared molecular pathways that could potentially have an implication beyond the field of progressive ataxias. ${ }^{13} \mathrm{~A}$ cross-disciplinary cooperation between clinicians, cell biologist and physiologist seems crucial in the definition of new therapeutic targets. Based on the postulated toxic gain-of-function hypothesis in the polyglutamine ataxias and animated by the breakthrough clinical success of antisense oligonucleotide (ASO) treatments in spinal muscular atrophy (SMA) and positive preliminary results in a Phase II clinical trial in Huntington disease (HD), different genetic approaches with the common goal of decreasing toxic protein levels are currently under investigation for SCAs. ${ }^{14-16}$ On the other hand, to combat the pathogenic loss-of-function, restoration of physiological frataxin protein levels appears to be a viable 
approach for FRDA patients. ${ }^{17}$ In addition, new agents aimed at improving the mitochondrial defects in FRDA are currently being assessed in clinical trials. ${ }^{18}$

This review will focus on the most prevalent dominant, recessive and X-linked ataxias in adults that are intriguingly all associated with pathological repetitive DNA sequences. We aim to outline the progress made in the molecular understanding of disease pathogenesis and the techniques that have made these advances possible. Lastly, we comment on the most recent developments in preclinical and clinical trials.

\section{Repeat expansions as a shared theme in the most prevalent ataxias}

\subsection{Repeat expansions in autosomal dominant ataxia}

ADCA are clinically characterized by a typically late-onset, progressive ataxia, but can present at any age. This incoordination is caused primarily by the degeneration of the cerebellum, which is variably associated with the involvement of other central and peripheral nervous system regions. ${ }^{19-21}$ In the individual patient, cerebellar ataxia is often accompanied by a variety of additional neurological symptoms. ${ }^{22}$

A plethora of causative mutations have been described in dominant inherited ataxias, including: conventional mutations (SCA5, SCA11, SCA13, SCA14, SCA19/22, SCA23, SCA26, SCA27, SCA28, SCA19, SCA35); rearrangements (SCA15, SCA16, SCA20); as well as expansions of variable length in intronic (SCA8, SCA10, SCA12, SCA31, SCA36) and exonic regions (SCA1, SCA2, SCA3, SAC6, SCA7, SCA17, DRPLA). ${ }^{23}$ The latter encompass the most common and best studied dominantly inherited ataxias. Together with other late-onset neurodegenerative diseases, namely HD and spinal-bulbar muscular atrophy, they form the group of nine known polyglutamine (polyQ) diseases. These disorders share an exonic $(\mathrm{CAG})_{\mathrm{n}}$ 
TR expansion in their respective disease genes. ${ }^{24-26}$ Simple repetitive elements are considered pathological if the number of triplets are greater than the number found in wild-type alleles. ${ }^{27}$ Once above a critical threshold, the excessive polyQ stretches in the translated proteins promote cell specific degeneration associated with a toxic gain-of-function at the protein and mRNA level, which leads to the pathological hallmark of these disorders, cellular aggregation. $^{28}$

In addition to pathogenic exonic TR expansions, repetitive DNA elements have more recently been discovered in untranslated regions of ataxia associated genes. ${ }^{29-33} \mathrm{SCA} 8$, for example, belongs to the group of pure adult-onset cerebellar ataxias. It is caused by a unique overlapping intronic CAG.CTG repeat in two complementary genes in the SCA 8 locus. ${ }^{34}$ The CTG expansion in the $A T X N 8 O S$ gene is transcribed into mRNA containing an expanded CUG repeat, while the CAG expansion in the $A T X N 8$ gene encodes a polyQ protein. ${ }^{32}$ This polyalanine was one of the initial proteins described in repeat associated non-ATG (RAN) translation. RAN translation occurs in different frames and causes accumulation of homopolymeric toxic SCA8-polyalanine peptides in vitro. ${ }^{35}$ This mechanism has since been described in other trinucleotide repeat diseases such SCA2, SCA7, HD, myotonic dystrophy, c9orf72-mediated amyotrophic lateral sclerosis (ALS) and frontotemporal dementia. ${ }^{35-39}$

\subsection{Repeat expansions in autosomal recessive ataxia}

FRDA is the most prevalent recessive ataxia and shares the causative agent of a TR expansion. At the genetic level, FRDA is caused by a homozygous transcribed, but not translated (GAA)n expansion located in the first intron of the $F X N$ gene in about $95 \%$ of patients. The residual individuals are compound heterozygote for a pathological expansion and a point mutation, insertion or deletion. ${ }^{5,40}$ In contrast to ADCA, onset of symptoms is typically around puberty, 
family history is often negative except for affected siblings and atrophy is observed mainly in the dorsal root ganglia, spinocerebellar and pyramidal tracts; with less predominant involvement of the cerebellum. Two recent studies suggest an underlying developmental component adding to degeneration of the dorsal columns. ${ }^{41,42}$ Together with axonal peripheral neuropathy, these neurodegenerative patterns contribute to hallmark clinical features, such as progressive unsteadiness of gait, bilateral Babinski sign and loss of deep tendon reflexes. ${ }^{43}$ Multisystem involvement is reflected by the high incidence of cardiomyopathy and insulin resistance that require close surveillance and active management. ${ }^{44}$ Late-onset presentations associated with smaller expansions on the shorter $F X N$ allele (GAA1) are increasingly well characterized, broadening the phenotypic spectrum of the disease. ${ }^{45}$

\subsection{Repeat expansions in $\mathrm{X}$-linked ataxia}

The most common and only recently recognized adult-onset X-linked ataxia is fragile Xassociated tremor/ataxia syndrome (FXTAS). The typical clinical presentation is characterized by intention tremor, gait ataxia, and parkinsonism in combination with variable cognitive decline. ${ }^{46}$ FXTAS is caused by what was previously considered as a premutation of 55 to 200 CGG.CCG repeats in the $5^{\prime}$ untranslated region of the FMR1 gene. ${ }^{46}$ Similarly to SCA8, RAN translation results in the transcription of toxic proteins (FXTAS-polyglycine, FXTASpolyproline, FXTAS-polyalanine) which have been detected in different brain regions. ${ }^{47}$ In addition, the RNA-mediated sequestering of proteins has been described. ${ }^{48}$ These pathological mechanisms are in contrast to the hypermethylation associated silencing of the FMR1 gene in fragile X-syndrome. ${ }^{49}$

\section{Advances in genetics and genomics}


Advances in the field of genome sequencing have led to the identification of novel genes, broadened the phenotypic spectrum of known ataxia associated genes, ameliorated genotypephenotype relationships and increased accuracy in prognosis. Recently, research in polyQ SCAs and FRDA has focused the influence of expansion configuration and genetic modifiers on age of disease onset (AOO), intergenerational instability and phenotypical presentation.

\subsection{Modifiers of AOO}

As mentioned above, the first genes identified by linkage analysis in ADCA share a dynamic CAG expansion that is translated into polyQ stretches. The threshold for pathogenicity is specific for each disease. The expansion of these structurally unstable TRs in the germline is referred to as genetic anticipation and is associated with higher levels of mutant proteins. ${ }^{27}$ This, in turn, translates into clinic in the form of increased disease severity, earlier manifestation of symptoms and reduced life expectancy in successive generations. ${ }^{50}$

Anticipation accounts for $50-80 \%$ of variance in $\mathrm{AOO}$; however, it does not explain variances in AOO observed in individuals with expansions of the same size. Once the length of the CAG repeat has been accounted for, the residual AOO variance can be considered as a heritable trait, implying the existence of genetic modifiers. ${ }^{51,52} \mathrm{~A}$ recent study identified non-pathological repeat lengths in other CAG-containing disease loci, that act in trans with wildtype alleles (SCA1, SCA6, SCA7), as modifiers of disease onset in 1255 patients from the EUROSCA cohort. ${ }^{53}$ These findings were partly replicated by other studies in smaller cohorts. ${ }^{54,55}$ However, overall conflicting evidence exists from the analysis of allelic associations across distinct populations. ${ }^{56-58}$ Inconclusive reports may reflect ethnical differences, small sample size or differences in methods. Moreover, correlation does not imply causation and functional relationship between genes necessitate conformation in in vitro or in vivo models. 
CAG repeat length and the presence of genetic modifiers are still insufficient to fully account for AOO variance. There is an increasing body of literature illustrating the influence of polyQ expansion configuration in the form of silent (CAA) and missense (CAT) insertions on disease onset. ${ }^{59}$ In the polyQ tract of SCA1, 98\% of the normal ATXN1 alleles (19-36 repeats) are interrupted by at least one histidine (CAT) trinucleotide when the tract exceeds 21 repeats. ${ }^{60} \mathrm{In}$ addition to stabilizing (CAG)n expansions, histidine interruptions appear to prevent or delay phenotypic presentation in individuals with borderline, and even clearly pathogenic repeat lengths. ${ }^{59}$ However, up to $11 \%$ of the patients in a SCA1 cohort harboured CAT interruptions in expanded alleles. ${ }^{61}$ Together with the observance of the loss of an interruption in maternal transmission, this implies an incomplete, more complex protective effect. In that cohort, the longest uninterrupted or pure repeat tract correlated best with disease onset and severity, highlighting the importance of repeat interruption analysis in SCA1 clinical practice. ${ }^{61}$ Interestingly, in two other TR diseases, repeat interruptions were not found to account for the variable age at onset. ${ }^{62,63}$

Most recently, a genome-wide association study found a significant association between AOO and genetic variants in DNA repair pathways. ${ }^{64}$ The modifying effects of these variants were examined in a cohort of subjects with HD and polyQ SCAs. The results yielded the most significant association with AOO when grouping all of the polyQ diseases, with rs3512 in FAN1 and rs1805323 in PMS2 being the top variants for HD and SCAs. ${ }^{64}$

FRDA is the only recessive TR disease, and thus is generally restricted to one generation. Even though anticipation is therefore not evident, there is a correlation between the repeat size of the shorter allele (GAA1) and AOO. ${ }^{44}$ Disease onset is inversely correlated with GAA1, with a 
prediction of a 2.6 years earlier onset for every 100 GAA repeats. ${ }^{65}$ The GAA1 repeat size correlates with frataxin protein levels, cardiac complications, AAO and disease progression, implicating that the shorter allele correlates best with the genotype-phenotype relationship. ${ }^{66-}$ ${ }^{68}$ Similarly to SCAs, GAA1 length explains approximately $50 \%$ of variance in AOO. ${ }^{67}$ In compound heterozygotes patients with loss-of-functions mutations, AOO is decreased. ${ }^{40}$

\subsubsection{Modifiers of intergenerational instability}

The complex molecular mechanisms and genetic factors influencing intergenerational instability likewise remain insufficiently understood. The tendency of polyQ repeats to expand is disease dependent (low in SCA17; high in SCA7 and DRPLA). With the exception of SCA8, a paternal expansion bias is observed in polyQ diseases that is mainly attributed to the greater number of mitotic divisions in spermatogenesis. ${ }^{69}$ In SCA2 and SCA7, cases of extreme anticipation result in infantile onset of a severe, multisystemic variant of the disease. This phenomenon has recently, and for the first time within the group of SCAs, been described through maternal transmission in SCA $7 .{ }^{70}$ Standard laboratory methods may not detect the very high number of repeats seen in infantile presentation, raising awareness of potentially false negative results in pre- and antenatal testing. ${ }^{70}$

Similarly, GAA-expansions in the $F X N$ gene in FRDA show instability in intergenerational transmission. In contrast to polyQ SCAs, paternally transmitted alleles tend to contract, whereas maternal alleles are equally likely to increase or decrease in repeat-size. ${ }^{71} \mathrm{~A}$ strong paternal contraction bias is likewise observed in Fragile-X syndrome, which is considered to be related to $\mathrm{CpG}$ methylation. ${ }^{69}$ 
In summary, extensive research performed on modifiers of AOO and intergenerational in trinucleotide associated ataxias points to repeat number, single-nucleotide polymorphism in DNA repair genes, repeat length in trans alleles and insertions. However, to date, CAT interruptions in SCA1 remain the only discovery that ameliorates prognosis for patients in clinical practice. ${ }^{61}$

\subsection{New insights in genotype-phenotypic presentation - implications beyond ataxia}

SCA2 serves as an excellent example of how the full phenotypic spectrum of distinct disorders and the influence of the composition of repeats are only beginning to be revealed. Patients with SCA2 harbour between 33 and 200 repeats in the $A T X N 2$ gene and typically present with ataxia accompanied by peripheral neuropathy and slowed ocular saccades. ${ }^{72}$ However, the presence of glutamine coding CAA interruptions within intermediate length repeat expansions in the ATXN2 gene has been shown to predispose to a parkinsonian phenotype in pedigrees of both Chinese and European heritage. ${ }^{73,74}$ Interrupted $A T X N 2$ tracts appear to have a far-reaching effect on other neurodegenerative diseases as well. Recent investigations focused on the modifying effect of ATXN2 on mutations in two ALS associated RNA regulation genes, c9orf72 and TARDBP. It has been demonstrated that long normal-length expansions of glutamines in the ATXN2 gene with CAA-interruptions serve as one of the most important risk factors for ALS, although the exact threshold for this effect remains controversial. ${ }^{75-77}$ Furthermore, experimental evidence demonstrating that $A T X N 2$ increases the cytotoxicity of TDP $-43^{75}$, a protein that is found aggregated in $95 \%$ of ALS patients, might serve as an explanation for this. ${ }^{78}$ More recently, the coexistent of an uninterrupted pathogenic AXTN2 expansion with 37 repeats and C9orf71 mutation was described in two individuals with parkinsonism, ataxia and dementia, thus complicating the contribution of CAA-interruptions in ATXN2 to phenotypic presentation of other neurodegenerative diseases. ${ }^{79}$ 
Contrarily to these recent findings, it has been long recognized that SCA3 patients occasionally present with prominent extrapyramidal features, in particular parkinsonism. ${ }^{80}$ Genetic variations have been implicated in these cases, and it has been suggested that polymorphism in Parkinson's related genes and the presence of an APOE $\varepsilon 2$ genotype may influence phenotypical presentation, although this has not been confirmed in larger cohorts. ${ }^{81}$ The role of ATXN3 as a deubiquitinating enzyme, thus involved in the same pathway as several Parkinson disease associated proteins, supports a probable interaction between these genes. ${ }^{82}$ In SCA17, the length of the $\mathrm{CAG} / \mathrm{CAA}$ tract, rather than the configuration of the repeats, appears to be correlated with the phenotype. ${ }^{83,84}$

\section{First-line genetic work-up}

Considering the marked phenotypic overlap between the different forms of ataxia and the variability of presentation even among patients with the same affected gene, genetic testing is the only way of establishing a conclusive diagnosis in the majority of patients. ${ }^{85}$ The choice of genetic wok should be guided by a detailed family history, ethnical background, physical examination, biochemical analysis and cerebral MRI studies ${ }^{86}$ Once acquired causes have been excluded, it is generally recommended to test for the most prevalent forms of autosomal dominant and recessive ataxias first, regardless of any known family history. ${ }^{86}$ These include: SCA1, SCA2, SCA3, SCA6, SCA7, DRPLA in the Asian population and FRDA. Reduced penetrance and repeat lengths of unknown pathogenicity, as described in several disorders including SCA6 and SCA8, necessitate careful interpretation of results. $59,87,88$

In the UK, the cost of first-line SCA genetic test for the polyQ test lies between $£ 160$ and $£ 452$ with a turnover between 14 and 28 working days. ${ }^{89}$ The targeted $F X N$ gene testing costs between $£ 80$ and $£ 420$ and has a turnover between 3 and 28 working days. ${ }^{89}$ Together, these 
disorders represent between 50 and $60 \%$ of hereditary ataxias worldwide. ${ }^{90,91}$ Thus, approximately half of the patients remain without a confirmed diagnosis after conventional first-line genetic testing. ${ }^{10,19}$ Mutations in rarer genes are often only investigated in cases with guiding clinical or biochemical findings. Moreover, in addition to the group of hereditary cerebellar ataxias, there are nearly 300 genetic conditions in which cerebellar ataxia can be an associated clinical feature ${ }^{92}$.

\section{Next-generation sequencing in clinical practice}

The vast number of involved genes and the molecular complexity of ataxias has recently encouraged the implementation of NGS in clinical genetic diagnosis. Indeed, neurological diseases in which a variety of mono-genetic mutations can result in a very uniform phenotype, such as ataxia, have profited enormously from the development of the massively paralleled sequencing methods. ${ }^{93}$ They have provided researchers and clinicians with an unprecedented opportunity to gain genetic information in base pair resolution across the genome in a single experiment at an increasingly affordable cost. NGS approaches range from targeted gene panels to whole exome (WES) and whole genome sequencing (WGS).

Németh at al. were the first to demonstrate the utility of targeted gene panels in familial and sporadic ataxia patients. ${ }^{94}$ The reported mean diagnostic delay of 18 years in patients who had tested negative for SCA1, SCA2, SCA3, SCA6, SCA7 and FRDA highlights the diagnostic journey of many individuals. An NGS panel capturing 117 known and putative ataxia genes confirmed a molecular diagnosis in $18 \%$ of patients, with the highest detection rate of $75 \%$ in familial cases with adolescent onset. ${ }^{94}$ Similar diagnostic rates have been reported in heterogeneous cohorts of ataxia patients who remained without diagnosis after standardised

genetic testing. ${ }^{91,95,96}$ WES represents an unbiased NGS approach, thus enabling the detection 
of novel genes. Using WES, positive results were obtained in 21 and $41 \%$ in heterogeneous cohorts of sporadic and familial ataxia patients in whom previous screening for common mutations had not yield any results. ${ }^{90,92,97}$ Across all NGS studies, a history of affected family members and an early AOO appear to be the most consistent factors associated with a higher diagnostic success rate.

WES has played a crucial role in the identification of rare ataxia-associated genes that appear to be more prevalent than hitherto expected, such as SYNE1, ANO10 and SPG7. Homozygous mutations in the mitochondrial AAA protease encoded by the $S P G 7$ gene are known to cause autosomal recessive hereditary spastic paraplegia, but were also founds by WES in ataxia patients from four independent cohorts in the UK and USA. ${ }^{90,92,97-99}$ Encouraged by these findings, it has since been shown that $S P G 7$ mutations are responsible for a significant percentage of unexplained ataxia cases, who may initially present without spasticitiy. ${ }^{100,101}$

The greatest limitations that currently prevent a widespread application of NGS in clinical practice in hereditary ataxia are the avalanche of generated data, the risk of incidental findings and the poor ability to sequence repetitive DNA stretches and regions with a high GuanineCytosine content. ${ }^{102}$ Firstly, debate remains around the critical evaluation of pathogenicity of variants of unknown significance through bioinformatics tools and functional analysis. ${ }^{103}$ This currently also represents the main cost factor and time-limiting step. ${ }^{6}$ Secondly, ethical challenges may arise from unexpected discoveries of potential medical relevance that are unrelated to the initial diagnostic indication. ${ }^{104}$ Several commercial and academic laboratories offer a combination of NGS implementation strategies by exome sequencing with a greater coverage of up to 1000 ataxia associated genes, thus reducing the risk for incidentals findings. ${ }^{105,106}$ Thirdly, it must be kept in mind that copy number variation, such trinucleotide repeat expansions, larger duplications and deletions, cannot reliably be detected by NGS 
sequencing techniques. ${ }^{107}$ Large repetitive regions fail to be aligned and mapped to a single position on the reference genome efficiently. Thus, prior exclusion of prevalent ataxias caused by trinucleotide repeat expansions remains paramount to date..$^{85,108}$

\subsection{Newly discovered genes through next-generation sequencing}

The success of NGS in a research setting is outlined by its role in the discovery of several new ataxia associated genes, including TGM6 (SCA36) ${ }^{29}, C A C N A 1 G(\mathrm{SCA} 42)^{109}$, ATP2B3 (Xlinked congenital cerebellar ataxia) ${ }^{110}, P N K P$ (ataxia with oculomotor apraxia type 4$)^{111}$, $A B C B 7$ (X-linked congenital cerebellar ataxia) ${ }^{112}, K C N D 3$ (SCA19/22) ${ }^{113}$ and TPP1 (SCAR7). Some of these genes have previously been described in the context of other neurological and non-neurological diseases, such as ceroid lipofuscinosis (TPP1) and Brugada syndrome type 9 (KCND3). Mechanism of genetic pleiotropy include different downstream effects of mutations within the same gene, modifier genes, and oligogenic inheritance. ${ }^{114}$ The best known example of genetic pleiotropy within the group of ataxias are $C A C N A 1 A$ mutations that can present as SCA6, episodic ataxia type II and familial hemiplegic migraine due to different functional downstream mechanisms. ${ }^{115}$

\section{From bench to bedside}

While new genes are being mapped, functional consequences and the reason behind the selective vulnerability of certain neurons to mutations in abundant transcribed ataxia-causing proteins remain largely uncharted. New insights into recurrent pathophysiological mechanism are expected to facilitate the discovery of therapeutic targets that may prove useful in several disorders in the future. Gene co-expression networks recently revealed two SCA gene enriched modules that included genes involved in the ubiquitin-proteasome pathway in granule cells and

calcium homeostasis in Purkinje cells. ${ }^{13}$ Dysfunction in DNA repair genes, disturbance of 
protein expression at the transcriptional and post-transcriptional level, and perturbed glutaminergic signaling represent additional emerging mechanisms of dominant and recessive ataxia associated genes. ${ }^{111,116-119}$ Intervening at the level of the mutant gene can bypass the obstacle of multiple downstream pathogenic pathways. These efforts have already advanced into clinical trials in other neurodegenerative diseases.

\subsection{Spinocerebellar ataxias}

The two main therapeutic pipelines in SCAs encompass pharmacological agents targeting disrupted downstream pathways and genetic therapy aiming to reduce toxic polyQ gene products. ${ }^{120}$ Given their monogenetic inheritance, the number of involved pathways and the insufficient knowledge of their individual contribution to neurodegeneration, intervening at the source of dysfunction by decreasing the expression level of mutant proteins appears to be a promising approach towards developing a disease-modifying therapy. ${ }^{11}$

\subsubsection{Gene-based approaches}

To date, preclinical research focuses on the modulation of protein expression through antisense oligonucleotides (ASOs) and RNA interference (RNAi). ASOs are short, single stranded DNA sequences that bind complementary mRNA transcripts through Watson-Crick hybridisation. The DNA-RNA complex recruits ubiquitously expressed RNase $\mathrm{H}$ enzymes, resulting in decreased expression of the targeted protein. ${ }^{121}$ Advances in delivery methods, allelespecificity and intracellular stability pave the way for safe and successful application in humans. ASO-based altering of SMN2 pre-mRNA splicing in children with infantile-onset SMA exemplifies a remarkably successful translation of genetic therapy from bench to bedside. ${ }^{14}$ The broad therapeutically potential of ASO-based therapy is further underlined by completed and ongoing clinical trials in SOD1-associated ALS ${ }^{122}$ and HD (NCT02519036) ${ }^{123}$. 
In relation to SCA, ASO-mediated removal of the toxic polyQ tract in the mutant ATXN3 gene via exon skipping has been successfully demonstrated in SCA3 fibroblasts ${ }^{124,125}$ and transgenic mice harbouring full-length human ATXN3 ${ }^{126,127}$, however amelioration of motor phenotype was not observed or not assessed. Strikingly, ATXN2-targeting ASOs significantly improved motor performance and extended the average survival not only in SCA2 ${ }^{128}$, but also in TDP43transgenic mice models of ALS. ${ }^{129}$ This could be advantageous over current strategies directly targeting ALS-associated mutated proteins such as SOD1 and TDP-43 directly, as they only account for $2-5 \%$ of ALS cases ${ }^{130}$ and are vital for development and cellular function respectively. ${ }^{131}$

RNAi is a naturally occurring post-transcriptional gene suppression process, which functions through non-coding double-stranded RNA sequences. RNAi effectors can be introduced into the cell in the form of short interfering RNAs, short hairpin RNAs or artificial miRNAs. ${ }^{132}$ Both non-allele specific and allele-specific RNAi approaches have demonstrated improvement on disease and molecular phenotype in SCA $7^{133,134}$ and SCA3 $3^{135,136}$ rodent models. Most recently, combined gene-knockdown-replacement therapy using mirtrons has been explored in fibroblast cell lines from SCA7 patients. ${ }^{137}$

\subsubsection{Completed and on-going clinical trails}

Five randomized, placebo-controlled clinical trials investigating the safety and efficacy of lithium $^{138,139}$, varenicline ${ }^{140}$, riluzole ${ }^{141}$ and trigriluzole ${ }^{142}$ have been completed in the last years. The former three drugs exemplify the increasing use of drug repurposing and are already licenced for other indications, namely bipolar disorders, nicotine addiction and ALS. In 2014, two separate groups reported no significant difference in the Scale for the Rating and Assessment of Ataxia (SARA) and Neurological Examination Score for the Assessment of 
Spinocerebellar Ataxia (NESSCA) after lithium treatment for 48 weeks in patients with SCA2 ${ }^{139}$ and SCA3. Varenicline, a partial agonist at $\alpha_{4} \beta_{2}$ neuronal nicotinic acetylcholine receptors, improved several SARA subscores in a small cohort of SCA3 patients compared to the placebo group. However, owing to the high dropout rate of $40 \%$ and the side effect profile, further studies are needed to assess clinical efficiacy. ${ }^{143}$ Romano and colleagues reported that the glutamate modulator Riluzole improved SARA scores in a heterogeneous group of patients with SCA and FRDA compared to a placebo group at 3 and 12 months. ${ }^{141}$ A phase III multicentric trial (NCT03347344) assessing its effect in SCA2 patients will start recruiting patients soon. ${ }^{144}$ However, in a phase II/III multicentre clinical trial, Trigriluzole, a prodrug formulation of riluzole, failed to differentiate from placebo on the primary and secondary endpoints after eight weeks of treatment. ${ }^{142}$ An open-label extension phase is currently on-going and results are expected at the end of $2018 .^{142}$

Preliminary results published from an open-label pilot trial administrating allogeneic adipose tissue-derived mesenchymal stem cells (MSCs) in six SCA3 patients reported safety and unaltered SARA scores at 12 months. In light of a reported annual decline of $3.00+-1.52$ in the SARA score reported from a natural history study of a similar cohort, this was cautiously interpreted as a stabilizing effect. ${ }^{145}$ The postulated neuroprotective mechanism of MSCs in

SCAs include secretion of neurotrophic factors, ${ }^{146,147}$ immune modulation and neuronal replacement. ${ }^{148}$ A phase II randomized controlled trial assessing safety and efficacy of MSCs in patients with SCA2 and SCA3 is currently recruiting patients in Taiwan (NCT02540655). ${ }^{149}$

\subsection{Friedreich's ataxia}

Based on the current understanding of the functional consequences of decreased FXN expression on iron-sulphur-cluster biogenesis and mitochondria function, the majority of studies in the past have focused on reducing reactive oxygen species (ROS). In brief, perturbed 
iron-sulphur-cluster assembly results in mitochondria dysfunction and iron accumulation in the membrane. Consequently, generated ROS triggers an avalanche of toxic downstream mechanisms such as lipid peroxidation. ${ }^{150,151}$ The failure to demonstrate consistent clinical benefit of the most extensively studied antioxidants in FRDA, coenzyme $\mathrm{Q}_{10}\left(\mathrm{CoQ}_{10}\right)$ and idebenone, has been, among other factors, attributed to their insufficient concentration both within cells and the central nervous system. ${ }^{152,153}$ Several ongoing clinical trials investigate new, tailored antioxidants with increased potency and improved bioavailability. However, as in SCAs, targeting only one factor of the incompletely understood downstream cascade may not be sufficient to improve symptoms. Again, pre-clinical research focuses on targeting the source of dysfunction, hence restoring FXN levels.

\section{$\underline{6.2 .1 \text { Clinical trials }}$}

Similar to coenzyme Q10 and idebenone, anti-oxidative properties of the currently investigated agent named EPI-743 (alpha-tocotrienol quinone) rely on a redox active para-benzoquinone ring that undergoes a two-electron cycling reaction. Promising results were obtained in an open-label trial in a small, heterogeneous cohort of patients with mitochondrial disease that included one patient with FRDA. ${ }^{154}$ A double-blind placebo-controlled trial including 61 patients with FRDA demonstrated the safety of EPI-743, however its primary endpoint of improvement of visual acuity was not met after 6 months. ${ }^{155}$ After completing an 18 month open-label extension phase, treated patients demonstrated improvement in the Friedreich's Ataxia Rating Scale (FARS)-NEURO, when compared to natural history data. ${ }^{140}$ RTA-408 (Omaveloxolone), an agent with anti-inflammatory and antioxidant properties, slows the degradation rate of nuclear factor erythroid-derived 2-related factor2 (Nrf2). Nrf2 functions as a transcription factor that targets genes, including antioxidant enzymes, that subsequently 
impact on mitochondrial function by reducing ROS production. ${ }^{156}$ RTA-408 clinical trials are currently recruiting for a phase II randomized controlled trial named MOXIe (NCT02255435). ${ }^{157}$ The part I results of the MOXIe trial demonstrated a dose-dependent improvement in a modulated FARS and in Nrf2 associated markers, such as CK and AST. This was also associated with improvements in mitochondrial and neurological function.

At present, there are many innovating clinical trials in the pipeline for therapeutic intervention in FRDA (Table 3). To tackle the low levels of FXN, a small cell-penetrant fusion protein, trans-activator transcription (TAT), has been engineered to shuttle synthetic FXN directly into the mitochondria. In frataxin knockout mouse models, an injection of TAT-frataxin resulted in a prolonged life span of up to 53\% longer with improved cardiac function, growth velocity and cardiac output ${ }^{158}$. An additional method to overcome the transcriptional deficit in FRDA is to directly provide encapsulated mRNA to cells, as naked mRNA is rapidly degraded, in order to raise mRNA levels. ${ }^{159}$ The application of FXN mRNA to cultured cells or animal models was successfully translated into the FXN protein. ${ }^{159}$ In principle, these techniques provide a novel method to replace the pathogenic depleted protein stores.

\subsubsection{Gene-based approaches}

Another valid approach to increase $\mathrm{FXN}$ is to reactivate the gene by inhibition of histone deacetylases (HDACs). Several studies of FRDA cell and animal models have shown that specific HDAC inhibitors reverse the epigenetic silencing of the frataxin gene resulting in downstream protein upregulation. ${ }^{160}$ RG2833, a synthetic HDAC inhibitor did not surpass Phase I clinical trials due to the adverse formation of metabolites in the body. ${ }^{161}$ Currently, a new generation of HDAC inhibitors are being developed to prevent harmful metabolites forming. 
ASOs that activate, rather than inhibit, gene expression have been developed for the use in FRDA. ${ }^{162}$ In FRDA patient-derived fibroblasts, the addition of synthetic duplex RNA, complementary to the GAA repeat region, increased expression of the frataxin gene mRNA by 3 - 4 fold and protein levels by 4 - 6 fold. This increase is consistent with wild-type frataxin levels. ${ }^{162}$ Similarly, single-stranded locked nucleic acid (LNA) oligonucleotides increased frataxin gene expression and protein levels in patient-derived fibroblasts. ${ }^{162}$ An alternative approach is to use oligonucleotides to eliminate the long noncoding RNA, which suppresses the frataxin gene expression. This method of frataxin upregulation couples the use of oligonucleotides for site recognition with the above mentioned RNase-H. Applying this technique to FRDA patient-derived fibroblasts has shown a significant upregulation of frataxin. In theory, oligonucleotide-based techniques can be used to modulate frataxin expression, but also possibly the downstream events. Therefore, this indicates the widespread use of antisense oligonucleotides as potential therapies in FRDA.

\section{Discussion}

Even though individually, hereditary ataxias belong to the group of rare disorders, taken together, they represent a prevalent group of disabling neurodegenerative diseases with significant economic burden. NGS has provided insight into the molecular cause of hereditary ataxias, the relationship with other neurodegenerative diseases ${ }^{75}$ and is currently making its way into clinical practice. ${ }^{94}$ The identification of novel ataxia associated genes in the future is expected, which has the potential to increase molecular diagnoses as a significant proportion of patients with hereditary ataxia still remain undiagnosed. ${ }^{99}$ There is a broad consensus that the transition of NGS from a research to a clinical setting possesses a great potential to increase the molecular diagnostic success rates and to improve the clinical management of patients who 
remain without diagnosis after standard genetic testing. The continuous decrease of WES costs, the reported higher diagnostic yield and its independence from an a priori hypothesis renders this technique especially suitable for the investigation of these genetically extremely heterogeneous disorders.

The theory of toxic gain-of-function caused by the transcription and accumulation of polyQ proteins certainly represents part of the pathological jigsaw, but increasingly emerges as an oversimplified portrayal of a far more complex process that needs further elaboration. ${ }^{163}$ For the first time, genetic modulation allows the direct targeting of the prima causa of these disorders. Important advances have been made in allele-specific targeting, as functional consequences of long-term downregulation of wild-type alleles of ataxia associated genes in humans are unknown. ${ }^{124,126}$ Moreover, the vast number of involved genes certainly complicates the generation of an agent that can be extrapolate to a larger patient population. Therefore, specific pathway-based approaches are still being pursued and many have advanced into clinical trials.

Regardless of the therapeutic approach, the development of disease-modifying agents create the need for robust, objective and easily accessible markers to monitor disease progression and assess treatment response. ${ }^{164}$ The successful quantification of the mutant huntingtin protein in the cerebrospinal fluid of HD patients and its relationship with disease progression has recently been described. ${ }^{165}$ Similar quantification of ataxia disease proteins are currently underway and could potentially serve as biomarkers for experimental gene modulation therapies. ${ }^{166}$

\section{Expert Opinion}

Over the last two decades, the progress in genetic sequencing has provided us with a better 
understanding of hereditary ataxia. Yet, at a closer look, these advances seem to have raised as many questions as they have answered. With the increased implementation of massively paralleled sequencing techniques in routine clinical practice, the number of patients with variants of unknown clinical significance has risen exponentially. To determine the pathogenicity of previously undescribed sequencing variants, time consuming and expensive functional analysis is frequently required. Allele segregation can be helpful in obtaining a conclusive decision, however family members are not always available for molecular testing. Systematic documentation of sequencing variants along with precise clinical information will enable faster segregation between causative and non-causative variants in the future.

Misinterpretation of variants of unknown significance can have a major impact on the clinical management of a patient and their families. The affected individual may receive the wrong therapy, prognosis and crucial information about recurrence risk. In patients with inconclusive genetic tests, biomarkers and functional assays could help to support the genetic results. The combined approach of laboratory markers and genetics has the potential to greatly increase the sensitivity of genetic tests and decrease expenses as well as time to diagnosis. Several helpful non-genetic tests are already established in diagnosing ataxic disorders, such as screening for elevated oxysterol markers in Niemann-Pick Type C. ${ }^{167}$ The need for blood tests to improve diagnosis has also been established in other disorders with underlying genetic mutations, such as cancer syndromes. ${ }^{168}$

Beyond ameliorating the interpretation of genetic testing, research in the field of biomarkers is urgently needed to optimize the design of clinical trials. As potential disease-modifying drugs are extensively investigated in preclinical and clinical studies, it will become crucial to identify easily accessible biomarkers to monitor the activity and therapeutic response of these agents. 
In summary, concomitant with the progress in genetic techniques, the field of ataxia could profit tremendously from the integration of robust biomarkers in both clinical diagnosis and therapeutic studies. Preliminary results of plasma biomarkers, such as neurofilaments, have shown promising potential in other neurodegenerative diseases and subsequently encourages the investigation of biomarkers in hereditary ataxia. ${ }^{169}$ 


\section{References}

1. Sandford, E. \& Burmeister, M. Genes and Genetic Testing in Hereditary Ataxias. Genes 5, $586-603(2014)$

2. Teive, H. A. G. \& Ashizawa, T. Primary and secondary ataxias. Curr. Opin. Neurol. 28, $413-422(2015)$

3. Harding, A. E. Genetic aspects of autosomal dominant late onset cerebellar ataxia. J. Med. Genet. 18, 436-441 (1981)

4. Orr, H. T., Chung, M.Y., Banfi, S., et al. Expansion of an unstable trinucleotide CAG repeat in spinocerebellar ataxia type 1. Nat. Genet. 4, 221-226 (1993)

* First identification and description of the causative mutation in SCA1.

5. Campuzano, V., Montermini, L., Moltò, M.D., et al. Friedreich's Ataxia: Autosomal Recessive Disease Caused by an Intronic GAA Triplet Repeat Expansion. Science 271, 1423-1427 (1996)

* First identification and description of the causative mutation in FRDA.

6. Didonna, A. \& Opal, P. Advances in Sequencing Technologies for Understanding Hereditary Ataxias: A Review. JAMA Neurol. 73, 1485-1490 (2016)

7. Coutelier, M., Stevanin, G. \& Brice, A. Genetic landscape remodelling in spinocerebellar ataxias: the influence of next-generation sequencing. J. Neurol. 262, 2382-2395 (2015)

8. Metzker, M. L. Sequencing technologies - the next generation. Nat. Rev. Genet. 11, 31 (2010)

9. Beaudin, M., Klein, C. J., Rouleau, et al. Systematic review of autosomal recessive ataxias and proposal for a classification. Cerebellum Ataxias 4, 3 (2017) 
10. Ruano, L., Melo, C., Silva, M. C. et al. The Global Epidemiology of Hereditary Ataxia and Spastic Paraplegia: A Systematic Review of Prevalence Studies. Neuroepidemiology 42, $174-183(2014)$

11. Paulson, H. L., Shakkottai, V. G., Clark, H. B., et al. Polyglutamine spinocerebellar ataxias - from genes to potential treatments. Nat. Rev. Neurosci. 18, 613 (2017)

12. He, Y., Alam, S.L., Proteasa, S.V., et al. Yeast Frataxin Solution Structure, Iron Binding, and Ferrochelatase Interaction. Biochemistry (Mosc.) 43, 16254-16262 (2004)

13. Bettencourt, C., Ryten, M., Forabosco, P., et al. Insights from cerebellar transcriptomic analysis into the pathogenesis of ataxia. JAMA Neurol. 71, 831-839 (2014)

14. Finkel, R. S., Chiriboga, C.A., Vajsar, J., et al. Treatment of infantile-onset spinal muscular atrophy with nusinersen: a phase 2, open-label, dose-escalation study. The Lancet $\mathbf{3 8 8 ,}$ $3017-3026(2016)$

*Breakthrough Phase 2 trial investigating antisense-oligonucleotide therapy in spinal muscular atrophy.

15. Mendell, J. R., Chiriboga, C.A., Vajsar J., et al. Single-Dose Gene-Replacement Therapy for Spinal Muscular Atrophy. N. Engl. J. Med. 377, 1713-1722 (2017)

16. Drug lowers deadly Huntington's disease protein. (2017). Available at:

http://www.ucl.ac.uk/ion/articles/news/hd-gene-silencing. (Accessed: 23rd January 2018)

*Positive preliminary results of a Phase II clinical trial assessing a huntingtinlowering drug in the treatment of Huntington's disease.

17. Perdomini, M., Belbellaa, B., Monassier, L., et al. Prevention and reversal of severe mitochondrial cardiomyopathy by gene therapy in a mouse model of Friedreich's ataxia. Nat. Med. 20, 542-547 (2014) 
18. Lynch, D., Farmer, J., Meyer, C., et al. Safety, Efficacy, and Pharmacodynamics of Omaveloxolone in Friedreich's Ataxia Patients (MOXle Trial): Part 1 Results. (2017)

19. Durr, A. Autosomal dominant cerebellar ataxias: polyglutamine expansions and beyond. Lancet Neurol. 9, 885-894 (2010)

20. Martins, C. R., Martinez, A.R.M., de Rezende, T.R., et al. Spinal Cord Damage in Spinocerebellar Ataxia Type 1. Cerebellum Lond. Engl. 16, 792-796 (2017)

21. Hernandez-Castillo, C. R., Diaz, R., Campos-Romo, A., et al. J. Neural correlates of ataxia severity in spinocerebellar ataxia type 3/Machado-Joseph disease. Cerebellum Ataxias 4, (2017)

22. Jacobi, H., du Montcel, S.T., Bauer, P., et al. Long-term disease progression in spinocerebellar ataxia types 1, 2, 3, and 6: a longitudinal cohort study. Lancet Neurol. $14,1101-1108(2015)$

23. Sun, Y.-M., Lu, C. \& Wu, Z.-Y. Spinocerebellar ataxia: relationship between phenotype and genotype - a review. Clin. Genet. 90, 305-314 (2016)

24. The Huntington's Disease Collaborative Research Group. A novel gene containing a trinucleotide repeat that is expanded and unstable on Huntington's disease chromosomes. Cell 72, 971-983 (1993)

25. Riley, B. E. \& Orr, H. T. Polyglutamine neurodegenerative diseases and regulation of transcription: assembling the puzzle. Genes Dev. 20, 2183-2192 (2006)

26. La Spada, A. R., Wilson, E. M., Lubahn, D. B., et al. Androgen receptor gene mutations in X-linked spinal and bulbar muscular atrophy. Nature 352, 77-79 (1991)

27. Budworth, H. \& McMurray, C. T. A Brief History of Triplet Repeat Diseases. Methods Mol. Biol. Clifton NJ 1010, 3-17 (2013) 
28. Dueñas, A. M., Goold, R. \& Giunti, P. Molecular pathogenesis of spinocerebellar ataxias. Brain J. Neurol. 129, 1357-1370 (2006)

29. Kobayashi, H., Abe, K., Matsuura, T., et al. Expansion of intronic GGCCTG hexanucleotide repeat in NOP56 causes SCA36, a type of spinocerebellar ataxia accompanied by motor neuron involvement. Am. J. Hum. Genet. 89, 121-130 (2011)

30. Sato, N., Amino, T., Kobayashi, K., et al. Spinocerebellar ataxia type 31 is associated with 'inserted' penta-nucleotide repeats containing (TGGAA)n. Am. J. Hum. Genet. 85, 544557 (2009)

31. Holmes, S. E., O'Hearn E.E., Mclnnis M.G., et al. Expansion of a novel CAG trinucleotide repeat in the $5^{\prime}$ region of PPP2R2B is associated with SCA12. Nat. Genet. 23, 391 (1999)

32. Moseley, M. L., Zu, T., Ikeda, Y., et al. Bidirectional expression of CUG and CAG expansion transcripts and intranuclear polyglutamine inclusions in spinocerebellar ataxia type 8. Nat. Genet. 38, 758-769 (2006)

33. Matsuura, T. Yamagata, T., Burgess, D.L., et al. Large expansion of the ATTCT pentanucleotide repeat in spinocerebellar ataxia type 10. Nat. Genet. 26, 191 (2000)

34. Ikeda, Y., Daughters, R. S. \& Ranum, L. P. W. Bidirectional expression of the SCA8 expansion mutation: One mutation, two genes. The Cerebellum 7, 150-158 (2008)

35. Zu, T., Gibbens, B., Doty, N.S., et al. Non-ATG-initiated translation directed by microsatellite expansions. Proc. Natl. Acad. Sci. U. S. A. 108, 260-265 (2011)

36. Bañez-Coronel, M., Ayhan, F., Tarabochia, A.D., et al. RAN Translation in Huntington Disease. Neuron 88, 667-677 (2015)

37. Zu, T., Liu Y., Bañez-Coronel, M., et al. RAN proteins and RNA foci from antisense transcripts in C9ORF72 ALS and frontotemporal dementia. Proc. Natl. Acad. Sci. U. S. A. 110, E4968-4977 (2013) 
38. Zu, T., Cleary, J.D., Liu, Y., et al. RAN Translation Regulated by Muscleblind Proteins in Myotonic Dystrophy Type 2. Neuron 95, 1292-1305.e5 (2017)

39. Scoles, D. R., Ho, M.H., Dansithong W., et al. Repeat Associated Non-AUG Translation (RAN Translation) Dependent on Sequence Downstream of the ATXN2 CAG Repeat. PloS One 10, e0128769 (2015)

40. Galea, C. A., Huq, A., Lockhart, P.J., et al. Compound heterozygous FXN mutations and clinical outcome in friedreich ataxia. Ann. Neurol. 79, 485-495 (2016)

41. Mascalchi, M., Bianchi, A., Ciulli, S., et al. Lower medulla hypoplasia in Friedreich ataxia: MR Imaging confirmation 140 years later. J. Neurol. 264, 1526-1528 (2017)

42. Koeppen, A. H., Becker, A. B., Qian, J., et al. Friedreich Ataxia: Hypoplasia of Spinal Cord and Dorsal Root Ganglia. J. Neuropathol. Exp. Neurol. 76, 101-108 (2017)

43. Anheim, M., Tranchant, C. \& Koenig, M. The autosomal recessive cerebellar ataxias. $N$. Engl. J. Med. 366, 636-646 (2012)

44. Dürr, A., Cossee, M., Agid, Y., et al. Clinical and Genetic Abnormalities in Patients with Friedreich's Ataxia. N. Engl. J. Med. 335, 1169-1175 (1996)

45. Lecocq, C., Charles, P., Azulay, J.P., et al. Delayed-onset Friedreich's ataxia revisited. Mov. Disord. Off. J. Mov. Disord. Soc. 31, 62-69 (2016)

46. Hagerman, R. J., Leehey, M., Heinrichs, W., et al. Intention tremor, parkinsonism, and generalized brain atrophy in male carriers of fragile X. Neurology 57, 127-130 (2001)

47. Krans, A., Kearse, M. G. \& Todd, P. K. Repeat-associated non-AUG translation from antisense CCG repeats in fragile X tremor/ataxia syndrome. Ann. Neurol. 80, 871-881 (2016) 
48. Sellier, C., Freyermuth, F., Tabet. R., et al. Sequestration of DROSHA and DGCR8 by expanded CGG RNA repeats alters microRNA processing in fragile $\mathrm{X}$-associated tremor/ataxia syndrome. Cell Rep. 3, 869-880 (2013)

49. Willemsen, R., Levenga, J. \& Oostra, B. A. CGG repeat in the FMR1 gene: size matters. Clin. Genet. 80, 214-225 (2011)

50. Friedman, J. E. Anticipation in hereditary disease: the history of a biomedical concept. Hum. Genet. 130, 705-714 (2011)

51. Figueroa, K. P., Coon, H., Santos, N., et al. Genetic analysis of age at onset variation in spinocerebellar ataxia type 2. Neurol. Genet. 3, (2017)

52. Pulst, S.-M., Santos, N., Wang, D., et al. Spinocerebellar ataxia type 2: polyQ repeat variation in the CACNA1A calcium channel modifies age of onset. Brain J. Neurol. 128, $2297-2303$ (2005)

53. Tezenas du Montcel, S., Durr, A., Bauer, P., et al. Modulation of the age at onset in spinocerebellar ataxia by CAG tracts in various genes. Brain 137, 2444-2455 (2014)

54. Chen, Z., Zheng, C., Long, Z., et al. (CAG)n loci as genetic modifiers of age-at-onset in patients with Machado-Joseph disease from mainland China. Brain 139, e41-e41 (2016)

55. van de Warrenburg, B. P., Hendriks, H., Dürr, A., et al. Age at onset variance analysis in spinocerebellar ataxias: a study in a Dutch-French cohort. Ann. Neurol. 57, 505-512 (2005)

56. Jardim, L., Silveira, I., Pereira, M.L., et al. Searching for modulating effects of SCA2, SCA6 and DRPLA CAG tracts on the Machado-Joseph disease (SCA3) phenotype. Acta Neurol. Scand. 107, 211-214 (2003) 
57. Raposo, M., Ramos, A., Bettencourt, C., et al. Replicating studies of genetic modifiers in spinocerebellar ataxia type 3: can homogeneous cohorts aid? Brain 138, e398-e398 (2015)

58. França, M. C., Emmel, V.E., D'Abreu, A., et al. Normal ATXN3 Allele but Not CHIP Polymorphisms Modulates Age at Onset in Machado-Joseph Disease. Front. Neurol. 3, (2012)

59. Zühlke, C., Dalski, A., Hellenbroich, Y., et al. Spinocerebellar ataxia type 1 (SCA1): phenotype-genotype correlation studies in intermediate alleles. Eur. J. Hum. Genet. EJHG 10, 204-209 (2002)

60. Chung, M. Y., Ranum, L.P., Duvick, L.A., et al. Evidence for a mechanism predisposing to intergenerational CAG repeat instability in spinocerebellar ataxia type I. Nat. Genet. 5, $254-258(1993)$

61. Menon, R. P., Nethisinghe, S., Faggiano, S., et al. The role of interruptions in polyQ in the pathology of SCA1. PLoS Genet. 9, e1003648 (2013)

\section{* Sequence interruptions within the pathogenic CAG repeat of SCA1 are identified as} modifiers of age at disease onset.

62. Fratta, P., Collins, T., Pemble, S., et al. Sequencing analysis of the spinal bulbar muscular atrophy CAG expansion reveals absence of repeat interruptions. Neurobiol. Aging 35, 443.e1-3 (2014)

63. Wiethoff, S., O'Connor, E., Haridy, N.A., et al. Sequencing analysis of the SCA6 CAG expansion excludes an influence of repeat interruptions on disease onset. J. Neurol. Neurosurg. Psychiatry (2018) 
64. Bettencourt, C., Hensman-Moss, D., Flower, M., et al. DNA repair pathways underlie a common genetic mechanism modulating onset in polyglutamine diseases. Ann. Neurol. 79, 983-990 (2016)

65. Reetz, K., Dogan, I., Costa, A.S., et al. Biological and clinical characteristics of the European Friedreich's Ataxia Consortium for Translational Studies (EFACTS) cohort: a cross-sectional analysis of baseline data. Lancet Neurol. 14, 174-182 (2015)

66. Pousset, F., Legrand, L., Monin, M.L., et al. A 22-Year Follow-up Study of Long-term Cardiac Outcome and Predictors of Survival in Friedreich Ataxia. JAMA Neurol. 72, 1334$1341(2015)$

67. Filla, A., De Michele, G., Cavalcanti, F., et al. The relationship between trinucleotide (GAA) repeat length and clinical features in Friedreich ataxia. Am. J. Hum. Genet. 59, $554-560(1996)$

68. Lazaropoulos, M., Dong, Y., Clark, E., et al. Frataxin levels in peripheral tissue in Friedreich ataxia. Ann. Clin. Transl. Neurol. 2, 831-842 (2015)

69. Pearson, C. E., Nichol Edamura, K. \& Cleary, J. D. Repeat instability: mechanisms of dynamic mutations. Nat. Rev. Genet. 6, 729-742 (2005)

70. Trang, H., Stanley, S.Y., Thorner, P., et al. Massive CAG Repeat Expansion and Somatic Instability in Maternally Transmitted Infantile Spinocerebellar Ataxia Type 7. JAMA Neurol. 72, 219-223 (2015)

71. Monrós, E., Moltó, M.D., Martínez, F., et al. Phenotype correlation and intergenerational dynamics of the Friedreich ataxia GAA trinucleotide repeat. Am. J. Hum. Genet. 61, 101-110 (1997) 
72. Geschwind, D. H., Perlman, S., Figueroa, C. P., et al. The prevalence and wide clinical spectrum of the spinocerebellar ataxia type 2 trinucleotide repeat in patients with autosomal dominant cerebellar ataxia. Am. J. Hum. Genet. 60, 842-850 (1997)

73. Wang, C., Xu, Y., Feng, X., et al. Linkage analysis and whole-exome sequencing exclude extra mutations responsible for the parkinsonian phenotype of spinocerebellar ataxia-2. Neurobiol. Aging 36, 545.e1-7 (2015)

74. Charles, P., Camuzat, A., Benammar, N., et al. Are interrupted SCA2 CAG repeat expansions responsible for parkinsonism? Neurology 69, 1970-1975 (2007)

75. Elden, A. C., Kim, H.J., Hart, M.P., et al. Ataxin-2 intermediate-length polyglutamine expansions are associated with increased risk for ALS. Nature 466, 1069-1075 (2010)

76. Conforti, F. L., Spataro, R., Sproviero, W., et al. Ataxin-1 and ataxin-2 intermediatelength PolyQ expansions in amyotrophic lateral sclerosis. Neurology 79, 2315-2320 (2012)

77. Neuenschwander, A. G., Thai, K. K., Figueroa, K. P., et al. Amyotrophic lateral sclerosis risk for spinocerebellar ataxia type 2 ATXN2 CAG repeat alleles: a meta-analysis. JAMA Neurol. 71, 1529-1534 (2014)

78. Neumann, M., Sampathu, D.M., Kwong, L.K., et al. Ubiquitinated TDP-43 in frontotemporal lobar degeneration and amyotrophic lateral sclerosis. Science 314, 130$133(2006)$

79. Zhang, M., Xi, Z., Misquitta, K., et al. C9orf72 and ATXN2 repeat expansions coexist in a family with ataxia, dementia, and parkinsonism. Mov. Disord. Off. J. Mov. Disord. Soc. 32, 158-162 (2017)

80. Giunti, P., Sweeney, M. G. \& Harding, A. E. Detection of the Machado-Joseph disease/spinocerebellar ataxia three trinucleotide repeat expansion in families with 
autosomal dominant motor disorders, including the Drew family of Walworth. Brain J. Neurol. 118 ( Pt 5), 1077-1085 (1995)

81. Bettencourt, C., Santos, C., Coutinho, P., et al. Parkinsonian phenotype in MachadoJoseph disease (MJD/SCA3): a two-case report. BMC Neurol. 11, 131 (2011)

82. Durcan, T. M. \& Fon, E. A. Ataxin-3 and Its E3 Partners: Implications for MachadoJoseph Disease. Front. Neurol. 4, (2013)

83. Stevanin, G., Fujigasaki, H., Lebre, A.S., et al. Huntington's disease-like phenotype due to trinucleotide repeat expansions in the TBP and JPH3 genes. Brain J. Neurol. 126, 15991603 (2003)

84. Kim, J.-Y., Kim. S.-Y., Kim, J.-M., et al. Spinocerebellar ataxia type 17 mutation as a causative and susceptibility gene in parkinsonism. Neurology 72, 1385-1389 (2009)

85. Sequeiros, J., Seneca, S. \& Martindale, J. Consensus and controversies in best practices for molecular genetic testing of spinocerebellar ataxias. Eur. J. Hum. Genet. 18, 1188$1195(2010)$

86. van de Warrenburg, B. P. C., van Gaalen, J., Boesch, S., et al. EFNS/ENS Consensus on the diagnosis and management of chronic ataxias in adulthood. Eur. J. Neurol. 21, 552-562 (2014)

87. Worth, P. F., Houlden, H., Giunti, P., et al. Large, expanded repeats in SCA8 are not confined to patients with cerebellar ataxia. Nat. Genet. 24, 214-215 (2000)

88. Van Alfen, N., Sinke, R.J., Zwarts, M.J., et al. Intermediate CAG repeat lengths $(53,54)$ for MJD/SCA3 are associated with an abnormal phenotype. Ann. Neurol. 49, 805-808 (2001) 
89. UK Genetic Testing. Find a test. UK Genetic Testing Network (2016). Available at: https://ukgtn.nhs.uk/find-a-test/search-by-disorder-gene/. (Accessed: 11th December 2017)

90. Pyle, A., Smertenko, T., Bargiela, D., et al. Exome sequencing in undiagnosed inherited and sporadic ataxias. Brain 138, 276-283 (2015)

91. Coutelier, M., Coarelli, G., Monin, M.L., et al. A panel study on patients with dominant cerebellar ataxia highlights the frequency of channelopathies. Brain 140, 1579-1594 (2017)

92. Fogel, B. L., Lee, H., Deignan J.L., et al. Exome Sequencing in the Clinical Diagnosis of Sporadic or Familial Cerebellar Ataxia. JAMA Neurol. 71, 1237-1246 (2014)

93. Krier, J. B., Kalia, S. S. \& Green, R. C. Genomic sequencing in clinical practice: applications, challenges, and opportunities. Dialogues Clin. Neurosci. 18, 299-312 (2016)

94. Németh, A. H., Kwasniewska, A.C., Lise, S., et al. Next generation sequencing for molecular diagnosis of neurological disorders using ataxias as a model. Brain J. Neurol. 136, 3106-3118 (2013)

95. Iqbal, Z., Rydning, S. L., Wedding, I.M., et al. Targeted high throughput sequencing in hereditary ataxia and spastic paraplegia. PLOS ONE 12, e0174667 (2017)

96. Hadjivassiliou, M., Martindale, J., Shanmugarajah, P., et al. Causes of progressive cerebellar ataxia: prospective evaluation of 1500 patients. J. Neurol. Neurosurg. Psychiatry 88, 301-309 (2017)

97. Keogh, M. J., Steele, H., Douroudis, K., et al. Frequency of rare recessive mutations in unexplained late onset cerebellar ataxia. J. Neurol. 262, 1822-1827 (2015) 
98. Koppen, M., Metodiev, M. D., Casari, G., et al. Variable and tissue-specific subunit composition of mitochondrial m-AAA protease complexes linked to hereditary spastic paraplegia. Mol. Cell. Biol. 27, 758-767 (2007)

99. van de Warrenburg, B. P., Schouten, M.I., de Bot, S.T., et al. Clinical exome sequencing for cerebellar ataxia and spastic paraplegia uncovers novel gene-disease associations and unanticipated rare disorders. Eur. J. Hum. Genet. EJHG 24, 1460-1466 (2016)

100. Pfeffer, G., Pyle, A., Griffin, H., et al. SPG7 mutations are a common cause of undiagnosed ataxia. Neurology 84, 1174-1176 (2015)

101. Choquet, K., Tétreault, M., Yang, S., et al. SPG7 mutations explain a significant proportion of French Canadian spastic ataxia cases. Eur. J. Hum. Genet. 24, 1016 (2016)

102. Guerreiro, R., Brás, J., Hardy, J., et al. Next generation sequencing techniques in neurological diseases: redefining clinical and molecular associations. Hum. Mol. Genet. 23, R47-R53 (2014)

103. Sandford, E., Li, J. Z. \& Burmeister, M. Evaluation of exome sequencing variation in undiagnosed ataxias. Brain 138, e383-e383 (2015)

104. Blackburn, H. L., Schroeder, B., Turner, C., et al. Management of Incidental Findings in the Era of Next-generation Sequencing. Curr. Genomics 16, 159-174 (2015)

105. GeneDX. Ataxia Xpanded Panel. (2017). Available at: https://www.genedx.com/wpcontent/uploads/2017/03/info_sheet_AtaxiaXpanded.pdf. (Accessed: 10th November 2017)

106. University of Chicago, Genetic Services Laboratories. Ataxia Exome Panel. (2017)

107. Chen, Y., Zhao, L., Wang, Y., et al. SeqCNV: a novel method for identification of copy number variations in targeted next-generation sequencing data. BMC Bioinformatics 18, $147(2017)$ 
108. Foo, J.-N., Liu, J.-J. \& Tan, E.-K. Whole-genome and whole-exome sequencing in neurological diseases. Nat. Rev. Neurol. 8, 508-517 (2012)

109. Coutelier, M., Blesneac, I., Monteil, A., et al. A Recurrent Mutation in CACNA1G Alters Cav3.1 T-Type Calcium-Channel Conduction and Causes Autosomal-Dominant Cerebellar Ataxia. Am. J. Hum. Genet. 97, 726-737 (2015)

110. Zanni, G., Calì, T., Kalscheuer, V.M., et al. Mutation of plasma membrane Ca2+ ATPase isoform 3 in a family with X-linked congenital cerebellar ataxia impairs Ca2+ homeostasis. Proc. Natl. Acad. Sci. U. S. A. 109, 14514-14519 (2012)

111. Bras, J., Alonso, I., Barbot, C., et al. Mutations in PNKP Cause Recessive Ataxia with Oculomotor Apraxia Type 4. Am. J. Hum. Genet. 96, 474-479 (2015)

112. Protasova, M. S., Grigorenko, A.P., Tyazhelova, T.V., et al. Whole-genome sequencing identifies a novel $A B C B 7$ gene mutation for $X$-linked congenital cerebellar ataxia in a large family of Mongolian ancestry. Eur. J. Hum. Genet. EJHG 24, 550-555 (2016)

113. Lee, Y.-C., Durr, A., Majczenko, K., et al. Mutations in KCND3 cause spinocerebellar ataxia type 22. Ann. Neurol. 72, 859-869 (2012)

114. Pang, S. Y., Teo, K.C., Hsu, J.S., et al. The role of gene variants in the pathogenesis of neurodegenerative disorders as revealed by next generation sequencing studies: a review. Transl. Neurodegener. 6, 27 (2017)

115. Giunti, P., Mantuano, E., Frontali, M., et al. Molecular mechanism of Spinocerebellar Ataxia type 6: glutamine repeat disorder, channelopathy and transcriptional dysregulation. The multifaceted aspects of a single mutation. Front. Cell. Neurosci. 9, 36 (2015)

116. Kitagawa, R. \& Kastan, M. B. The ATM-dependent DNA damage signaling pathway. Cold Spring Harb. Symp. Quant. Biol. 70, 99-109 (2005) 
117. Jones, L., Houlden, H. \& Tabrizi, S. J. DNA repair in the trinucleotide repeat disorders. Lancet Neurol. 16, 88-96 (2017)

118. Lokanga, R. A., Zhao, X.-N. \& Usdin, K. The mismatch repair protein MSH2 is rate limiting for repeat expansion in a fragile X premutation mouse model. Hum. Mutat. 35, 129-136 (2014)

119. Shuvaev, A. N., Hosoi, N., Sato, Y., et al. Progressive impairment of cerebellar mGluR signalling and its therapeutic potential for cerebellar ataxia in spinocerebellar ataxia type 1 model mice. J. Physiol. 595, 141-164 (2017)

120. Pulst, S. M. Degenerative ataxias, from genes to therapies: The 2015 Cotzias Lecture. Neurology 86, 2284-2290 (2016)

121. Schoch, K. M. \& Miller, T. M. Antisense Oligonucleotides: Translation from Mouse Models to Human Neurodegenerative Diseases. Neuron 94, 1056-1070 (2017)

122. Miller, T. M., Pestronk, A., David, W., et al. An antisense oligonucleotide against SOD1 delivered intrathecally for patients with SOD1 familial amyotrophic lateral sclerosis: a phase 1, randomised, first-in-man study. Lancet Neurol. 12, 435-442 (2013)

123. Safety, Tolerability, Pharmacokinetics, and Pharmacodynamics of IONIS-HTTRx in Patients With Early Manifest Huntington's Disease - ClinicalTrials.gov. Available at: https://clinicaltrials.gov/ct2/show/NCT02519036. (Accessed: 8th December 2017)

124. Toonen, L. J. A., Schmidt, I., Luijsterburg, M. S., et al. Antisense oligonucleotidemediated exon skipping as a strategy to reduce proteolytic cleavage of ataxin-3. Sci. Rep. 6, 35200 (2016)

125. Evers, M. M., Tran, H.D., Zalachoras, I., et al. Ataxin-3 protein modification as a treatment strategy for spinocerebellar ataxia type 3: removal of the CAG containing exon. Neurobiol. Dis. 58, 49-56 (2013) 
126. Toonen, L. J. A., Rigo, F., van Attikum, H., et al. Antisense Oligonucleotide-Mediated Removal of the Polyglutamine Repeat in Spinocerebellar Ataxia Type 3 Mice. Mol. Ther. Nucleic Acids 8, 232-242 (2017)

127. Moore, L. R., Rajpal, G., Dillingham, I.T., et al. Evaluation of Antisense Oligonucleotides Targeting ATXN3 in SCA3 Mouse Models. Mol. Ther. Nucleic Acids 7, 200-210 (2017)

128. Pulst, S. M. Degenerative ataxias, from genes to therapies. Neurology $86,2284-2290$ (2016)

129. Becker, L. A., Huang, B., Bieri, G., et al. Therapeutic reduction of ataxin-2 extends lifespan and reduces pathology in TDP-43 mice. Nature 544, 367-371 (2017)

*Suppression of ataxin-2 reduces aggregation of TDP-43 and increases survival in TDP43 mice.

130. Rosen, D. R. Mutations in Cu/Zn superoxide dismutase gene are associated with familial amyotrophic lateral sclerosis. Nature 362, 59 (1993)

131. Kraemer, B. C., Schuck. T., Wheeler, J.M., et al. Loss of murine TDP-43 disrupts motor function and plays an essential role in embryogenesis. Acta Neuropathol. (Berl.) 119, 409-419 (2010)

132. Kraemer, B. C., Schuck. T., Wheeler, J.M., et al. Loss of murine TDP-43 disrupts motor function and plays an essential role in embryogenesis. Acta Neuropathol. (Berl.) 119, 409-419 (2010)

133. Ramachandran, P. S., Boudreau, R. L., Schaefer, K. A., et al. Nonallele specific silencing of ataxin-7 improves disease phenotypes in a mouse model of SCA7. Mol. Ther. J. Am. Soc. Gene Ther. 22, 1635-1642 (2014) 
134. Scholefield, J., Greenberg, L.J., Weinberg, M.S., et al. Design of RNAi Hairpins for Mutation-Specific Silencing of Ataxin-7 and Correction of a SCA7 Phenotype. PLOS ONE 4, e7232 (2009)

135. Costa Mdo C., Luna-Cancalon, K., Fischer, S., et al. Toward RNAi therapy for the polyglutamine disease Machado-Joseph disease. Mol. Ther. J. Am. Soc. Gene Ther. 21, 1898-1908 (2013)

136. Nóbrega, C., Nascimento-Ferreira, I., Onofre, I., et al. Silencing mutant ataxin-3 rescues motor deficits and neuropathology in Machado-Joseph disease transgenic mice. PloS One 8, e52396 (2013)

137. Curtis, H. J., Seow, Y., Wood, M. J. A., et al. Knockdown and replacement therapy mediated by artificial mirtrons in spinocerebellar ataxia 7. Nucleic Acids Res. 45, 7870$7885(2017)$

138. Saute, J. A., de Castilhos, R.M., Monte, T.L., et al. A randomized, phase 2 clinical trial of lithium carbonate in Machado-Joseph disease. Mov. Disord. Off. J. Mov. Disord. Soc. 29, 568-573 (2014)

139. Saccà, F. et al. A randomized controlled pilot trial of lithium in spinocerebellar ataxia type 2. J. Neurol. 262, 149-153 (2015).

140. Zesiewicz, T. A., Greenstein, P.E., Sullivan, K.L., et al. A randomized trial of varenicline (Chantix) for the treatment of spinocerebellar ataxia type 3. Neurology 78, 545-550 (2012)

141. Romano, S., Coarelli, G., Marcotulli, C., et al. Riluzole in patients with hereditary cerebellar ataxia: a randomised, double-blind, placebo-controlled trial. Lancet Neurol. 14, 985-991 (2015) 
142. BIOHAVEN REPORTS NEGATIVE TOPLINE DATA FROM SPINOCEREBELLAR ATAXIA (SCA) PHASE 2/3 TRIAL

143. Saute, J. A. M. \& Jardim, L. B. Machado Joseph disease: clinical and genetic aspects, and current treatment. Expert Opin. Orphan Drugs 3, 517-535 (2015)

144. Clinical Trial With Riluzole in Spinocerebellar Ataxia Type 2 (ATRIL) -

ClinicalTrials.gov. Available at: https://clinicaltrials.gov/ct2/show/NCT03347344. (Accessed: 6th December 2017)

145. Tsai, Y.A., Liu, R.S., Lirng, J.F., et al. Treatment of Spinocerebellar Ataxia with Mesenchymal Stem Cells: A Phase I/Ila Clinical Study. Cell Transplant. 26, 503-512 (2017)

146. Chang, Y.K., Chen, M.H., Chiang, Y.H., et al. Mesenchymal stem cell transplantation ameliorates motor function deterioration of spinocerebellar ataxia by rescuing cerebellar Purkinje cells. J. Biomed. Sci. 18, 54 (2011)

147. Zhang, M.-J., Sun, J.J., Qian, L., et al. Human umbilical mesenchymal stem cells enhance the expression of neurotrophic factors and protect ataxic mice. Brain Res. $1402,122-131(2011)$

148. Mendonça, L. S., Nóbrega, C., Hirai, H., et al. Transplantation of cerebellar neural stem cells improves motor coordination and neuropathology in Machado-Joseph disease mice. Brain J. Neurol. 138, 320-335 (2015)

149. Efficacy and Safety Study of Stemchymal ${ }^{\circledR}$ in Polyglutamine Spinocerebellar Ataxia Full Text View - ClinicalTrials.gov. Available at: https://clinicaltrials.gov/ct2/show/NCT02540655. (Accessed: 6th December 2017) 
150. Cotticelli, M. G., Crabbe, A. M., Wilson, R. B., et al. Insights into the role of oxidative stress in the pathology of Friedreich ataxia using peroxidation resistant polyunsaturated fatty acids. Redox Biol. 1, 398-404 (2013)

151. Abeti, R., Parkinson, M.H., Hargreaves, I.P., et al. 'Mitochondrial energy imbalance and lipid peroxidation cause cell death in Friedreich's ataxia'. Cell Death Dis. 7, e2237 (2016)

152. Lynch, D. R., Perlman, S. L. \& Meier, T. A phase 3, double-blind, placebo-controlled trial of idebenone in friedreich ataxia. Arch. Neurol. 67, 941-947 (2010)

153. Lagedrost, S. J., Sutton, M.S., Cohen, M.S., et al. Idebenone in Friedreich ataxia cardiomyopathy-results from a 6-month phase III study (IONIA). Am. Heart J. 161, 639645.e1 (2011)

154. Enns, G. M., Kinsman, S.L., Perlman, S.L., et al. Initial experience in the treatment of inherited mitochondrial disease with EPI-743. Mol. Genet. Metab. 105, 91-102 (2012)

155. Zesiewicz, T., Allison, K., Jahan, I., et al. EPI-743 Improves Motor Function and CNS Biomarkers in PD: Results from a Phase 2A Pilot Trial (S40.004). Neurology 86, S40.004 (2016)

156. Holmström, K. M., Kostov, R. V. \& Dinkova-Kostova, A. T. The multifaceted role of Nrf2 in mitochondrial function. Curr. Opin. Toxicol. 1, 80-91 (2016)

157. RTA 408 Capsules in Patients With Friedreich's Ataxia - MOXIe - ClinicalTrials.gov. Available at: https://clinicaltrials.gov/ct2/show/NCT02255435. (Accessed: 9th December 2017)

158. Vyas, P. M., Tomamichel, W.J., Pride, P.M., et al. A TAT-frataxin fusion protein increases lifespan and cardiac function in a conditional Friedreich's ataxia mouse model. Hum. Mol. Genet. 21, 1230-1247 (2012) 
159. Nabhan, J. F., Wood, K.M., Rao, V.P., et al. Intrathecal delivery of frataxin mRNA encapsulated in lipid nanoparticles to dorsal root ganglia as a potential therapeutic for Friedreich's ataxia. Sci. Rep. 6, 20019 (2016)

160. Soragni, E. \& Gottesfeld, J. M. Translating HDAC inhibitors in Friedreich's ataxia. Expert Opin. Orphan Drugs 4, 961-970 (2016)

161. Soragni, E., Miao, W., ludicello, M., et al. Epigenetic therapy for Friedreich ataxia. Ann. Neurol. 76, 489-508 (2014)

162. Li, L., Matsui, M. \& Corey, D. R. Activating frataxin expression by repeat-targeted nucleic acids. Nat. Commun. 7, 10606 (2016)

163. Shao, J. \& Diamond, M. I. Polyglutamine diseases: emerging concepts in pathogenesis and therapy. Hum. Mol. Genet. 16 Spec No. 2, R115-123 (2007)

164. Zhang, K. \& Rothstein, J. D. Neurodegenerative disease: Two-for-one on potential therapies. Nature 544, 302 (2017)

165. Wild, E. J., Boggio, R., Langbehn, D., et al. Quantification of mutant huntingtin protein in cerebrospinal fluid from Huntington's disease patients. J. Clin. Invest. 125, 1979-1986 (2015)

166. Keiser, M. S., Kordasiewicz, H. B. \& McBride, J. L. Gene suppression strategies for dominantly inherited neurodegenerative diseases: lessons from Huntington's disease and spinocerebellar ataxia. Hum. Mol. Genet. 25, R53-64 (2016)

167. Porter, F. D., Scherrer, D.E., Lanier M.H., et al. Cholesterol oxidation products are sensitive and specific blood-based biomarkers for Niemann-Pick C1 disease. Sci. Transl. Med. 2, 56ra81 (2010)

168. Cohen, J. D., Li, L., Wang, Y., et al. Detection and localization of surgically resectable cancers with a multi-analyte blood test. Science eaar3247 (2018) 
169. Byrne, L. M., Rodrigues, F.B., Blennow, K., et al. Neurofilament light protein in blood as a potential biomarker of neurodegeneration in Huntington's disease: a retrospective cohort analysis. Lancet Neurol. 16, 601-609 (2017 


\section{Prevalence}

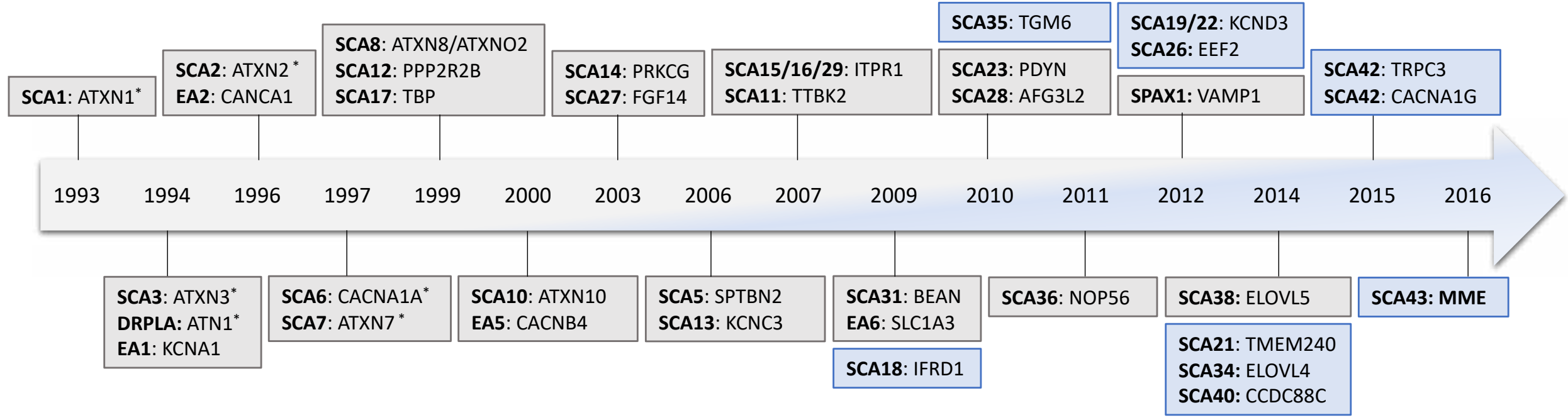

Figure 1. Timeline of gene discoveries in autosomal dominant inherited ataxia. Grey background indicates genes that were discovered by positional cloning and subsequent Sanger sequencing. Blue background indicates genes that were identified by nextgeneration sequencing approaches. The most prevalent ataxias were discovered with conventional sequencing techniques, whereas novel genes generally underlie a small proportion of ataxia patients. * Disorders that are part of first-line genetic testing. SCA Spinocerebellar ataxia. EA Episodic ataxia. DRPLA Dentatorubral-pallidoluysian atrophy. SPAX1 Spastic ataxia type 1. 


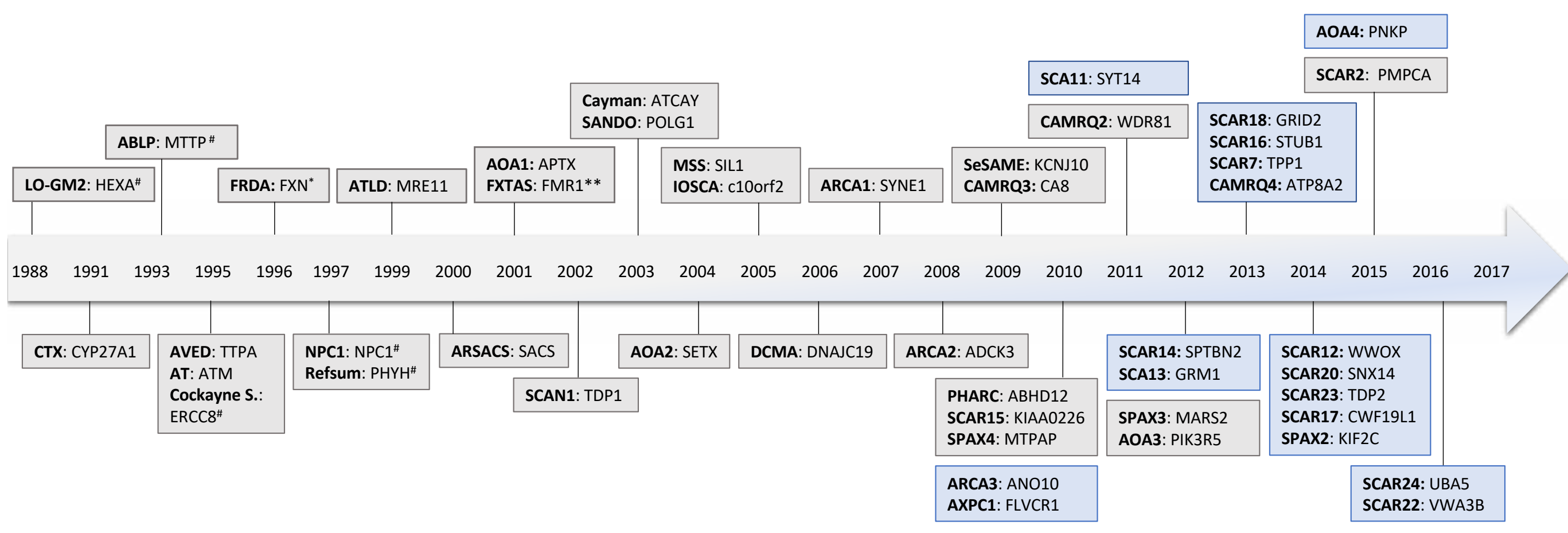

Figure 2. Timeline of gene discoveries in autosomal recessive inherited ataxias. Grey background indicates genes that were discovered by positional cloning and subsequent Sanger sequencing. Blue background indicates genes that were identified by next-generation sequencing approaches. The most prevalent ataxias were discovered with conventional sequencing techniques, whereas novel genes generally underlie a small proportion of ataxia patients. ${ }^{*}$ Disorders that are part of first-line genetic testing. \# Complex disorders that present with ataxia as a prominent clinical feature. ${ }^{* *}$ X-chromosomal inheritance. 
Figure 2. Timeline of gene discoveries in autosomal recessive inherited ataxias. Grey background indicates genes that were discovered by positional cloning and subsequent Sanger sequencing. Blue background indicates genes that were identified by next-generation sequencing approaches. The most prevalent ataxias were discovered with conventional sequencing techniques, whereas novel genes generally underlie a small proportion of ataxia patients. ${ }^{*}$ Disorders that are part of first-line genetic testing. \# Complex disorders that present with ataxia as a prominent clinical feature. ${ }^{* *}$ X-chromosomal inheritance. LO-GM2 late-onset Tay-Sachs. CTX Cerebrotendinous xanthomatosis. ABLP Abetaliproteinemia. AVED ataxia with Vitamin E deficiency. AT Ataxia telangiectasia. Cockayne S. Cockayne syndrome. FRDA Friedreich's ataxia. NPC1 Nieman Pick type C1. Refsum Refsum disorder. ATLD Ataxia-telangiectasia-like disorder. ARSACS Autosomal recessive spastic ataxia of Charlevoix-Saguenay. AOA Ataxia with oculomotor apraxia. FXTAS Fragile - tremor/ataxia syndrome. SCAN1 Spinocerebellar ataxia with axonal neuropathy. Cayman Cayman ataxia. SANDO Sensory ataxic neuropathy with dysarthria/dysphagia. MSS Marinesco-Sjögren syndrome. IOSCA Infantile-onset spinocerebellar ataxia. DCMA Dilated cardiomyopathy with ataxia. ARCA Autosomal recessive cerebellar ataxia. SeSAME Seizures, Sensorineural deafness, Ataxia, Mental retardation and Electrolyte imbalance. CAMRQ Cerebellar ataxia, mental retardation, and dysequilibrium syndrome. PHARC Polyneuropathy, hearing loss, ataxia, retinitis pigmentosa, and cataract. SCAR Autosomal recessive spinocerebellar ataxia. SPAX Spastic ataxia. 


\begin{tabular}{|c|c|c|c|c|c|}
\hline Disease & Gene & Loci & Mutation & Function & Comments \\
\hline \multicolumn{6}{|c|}{ ADCA I - Cerebellar Ataxias with additional features } \\
\hline DRPLA & ATN1 & $12 q 13.31$ & CAG exp. & $\begin{array}{l}\text { Transcriptional } \\
\text { activator }\end{array}$ & $\begin{array}{l}\text { Myoclonus, epilepsy, } \\
\text { choreoathetosis, intellectual } \\
\text { decline; DD Huntington disease }\end{array}$ \\
\hline SCA1 & ATXN1 & $6 p 22.3$ & CAG exp. & $\begin{array}{l}\text { Transcriptional } \\
\text { repression, involved in } \\
\text { developmental } \\
\text { processes }\end{array}$ & $\begin{array}{l}\text { Fast progression with early bulbar } \\
\text { involvement, pyramidal } \\
\text { involvement }\end{array}$ \\
\hline SCA2 & ATXN2 & $12 q 24.13$ & CAG exp. & $\begin{array}{l}\text { Translational } \\
\text { modification }\end{array}$ & $\begin{array}{l}\text { Saccade slowing, peripheral } \\
\text { neuropathy }\end{array}$ \\
\hline SCA3 & ATXN3 & $14 p 32.12$ & CAG exp. & Ubiquitin-protease & $\begin{array}{l}\text { Also known as Machado-Jacob } \\
\text { disease; parkinsonian phenotype } \\
\text { in a subgroup of patients }\end{array}$ \\
\hline SCA4 & Unknown & $16 q 22.1$ & Unknown & Unknown & Sensory axonal neuropathy \\
\hline SCA5 & SPTBN2 & $11 q 13.2$ & Deletion, MM & $\begin{array}{l}\text { Forming of neuronal } \\
\text { membrane skeleton }\end{array}$ & $\begin{array}{l}\text { Early-onset severe phenotype } \\
\text { described in de novo missense } \\
\text { mutations }\end{array}$ \\
\hline SCA10 & ATXN10 & $22 q 13.31$ & ATTCT exp. & $\begin{array}{l}\text { Activation of the } \\
\text { mitogen-activated } \\
\text { protein kinase cascade }\end{array}$ & $\begin{array}{l}\text { Seizures; reports restricted to } \\
\text { Latin American population }\end{array}$ \\
\hline SCA12 & PPP2R2B & $5 q 32$ & $\begin{array}{l}\text { CAG exp. } \\
\text { (non-coding) }\end{array}$ & Protein phosphatase & $\begin{array}{l}\text { Action tremor; common in Indian } \\
\text { ancestry }\end{array}$ \\
\hline SCA13 & KCNC3 & $19 q 13.33$ & MM & $\begin{array}{l}\text { Membrane potential } \\
\text { regulation }\end{array}$ & Occasionally intellectual disability \\
\hline SCA17 & TBP & $6 q 27$ & CAG exp. & $\begin{array}{l}\text { DNA-binding subunit } \\
\text { of RNA-polymerase II } \\
\text { transcription factor }\end{array}$ & $\begin{array}{l}\text { Dementia, chorea, psychiatric } \\
\text { symptoms }\end{array}$ \\
\hline SCA18 & Unknown & $7 q 22.23$ & Unknown & Unknown & $\begin{array}{l}\text { Sensory-motor neuropathy, } \\
\text { atrophy, nystagmus }\end{array}$ \\
\hline SCA19/22 & KCND3 & $1 p 13.2$ & MM & $\begin{array}{l}\text { Voltage-gated } \\
\text { potassium channel }\end{array}$ & $\begin{array}{l}\text { Slow progression, rare cognitive } \\
\text { impairment, myoclonus, pyramidal } \\
\text { signs }\end{array}$ \\
\hline SCA20 & Unknown & $11 q 12$ & Duplication & Unknown & Dysphonia, bradykinesia \\
\hline SCA21 & TMEM240 & $1 p 36.33$ & MM & $\begin{array}{l}\text { Transmembrane } \\
\text { protein }\end{array}$ & Intellectual impairment \\
\hline SCA23 & PDYN & 20p13 & MM, FS & Synaptic transmission & $\begin{array}{l}\text { Dysarthria, myoclonus, peripheral } \\
\text { neuropathy }\end{array}$ \\
\hline SCA25 & Unknown & $2 p 15-21$ & Unknown & Unknown & Sensory neuropathy \\
\hline SCA26 & EEF2 & $19 p 13.3$ & MM & Translation & Sensory neuropathy, dysarthria \\
\hline
\end{tabular}




\begin{tabular}{|c|c|c|c|c|c|}
\hline SCA27 & FGF14 & 13q13.1 & MM & $\begin{array}{l}\text { Cell growth and } \\
\text { survival }\end{array}$ & $\begin{array}{l}\text { Cognitive deficits, dyskinesia, } \\
\text { tremor }\end{array}$ \\
\hline SCA28 & AFG3L2 & $18 p 11.21$ & MM & $\begin{array}{l}\text { ATP-dependent } \\
\text { protease }\end{array}$ & $\begin{array}{l}\text { Ophthalmoparesis, ptosis; } \\
\text { Allelic to SPAX5 }\end{array}$ \\
\hline SCA29 & ITPR1 & $3 p 26.1$ & MM & $\mathrm{Ca}^{2+}$ signalling & $\begin{array}{l}\text { Slow progressive, learning deficits; } \\
\text { Allelic to SCA15 }\end{array}$ \\
\hline SCA34 & ELOVL4 & $5 q 14$ & MM & Lipid metabolism & $\begin{array}{l}\text { Erythrokeratodermia variabilis } \\
\text { described }\end{array}$ \\
\hline SCA35 & TGM6 & $20 p 13$ & MM & Protein crosslinking & Hyperreflexia, dystonia \\
\hline SCA36 & NOP56 & $20 p 13$ & $\begin{array}{l}\text { GGGCCTG exp. } \\
\text { (non-coding) }\end{array}$ & RNA-procession & Fasciculations, tongue atrophy \\
\hline SCA42 & CACNA1G & $17 q 21.33$ & MM & $\mathrm{Ca}^{2+}$ signalling & Mild pyramidal signs \\
\hline SCA43 & MME & $3 q 25.2$ & MM & $\begin{array}{l}\text { Zinc-dependent } \\
\text { metalloprotease }\end{array}$ & Reported in one family. \\
\hline \multicolumn{6}{|c|}{ ADCA II - Cerebellar ataxia swith pigmental retinal degeneration } \\
\hline Disease & Gene & Loci & Mutation & Function & Clinic \\
\hline SCA7 & ATXN7 & $3 p 14.1$ & CAG exp. & Transcription factor & Visual loss caused by retinopathy \\
\hline \multicolumn{6}{|c|}{ ADCA III - 'Pure' cerebellar ataxias } \\
\hline SCA6 & CACNA1A & $19 p 13.13$ & CAG exp. & $\begin{array}{l}\text { Voltage-gated calcium } \\
\text { channel }\end{array}$ & $\begin{array}{l}\text { Allelic to EA2 and familial } \\
\text { hemiplegic migraine }\end{array}$ \\
\hline SCA8 & $\begin{array}{l}\text { ATXN8OS } \\
\text { ATXN8 }\end{array}$ & $13 q 21$ & $\begin{array}{l}\text { CTA.CTG exp. } \\
\text { (non-coding) }\end{array}$ & $\begin{array}{l}\text { Non-protein coding; } \\
\text { Unknown }\end{array}$ & $\begin{array}{l}\text { Standardized genetic test not } \\
\text { established. }\end{array}$ \\
\hline SCA11 & TTBK2 & $15 q 15.2$ & Deletion & Tau phosphorylation & Benign course \\
\hline SCA14 & PRKCG & $19 q 13.42$ & MM & $\begin{array}{l}\text { Protein } \\
\text { phosphorylation }\end{array}$ & Myoclonus \\
\hline SCA15/16 & ITPR1 & $3 p 26.1$ & MM, Deletion & $\mathrm{Ca}^{2+}$ signalling & $\begin{array}{l}\text { Slow progression, occasionally } \\
\text { intellectual disability }\end{array}$ \\
\hline SCA31 & BEAN1 & $16 q 22$ & $\begin{array}{l}\text { TGGAA exp. } \\
\text { (non-coding) }\end{array}$ & Ubiquitin-pathway & Sensorineural hearing loss \\
\hline SCA38 & ELOVL5 & $6 p 12$ & MM & Lipid metabolism & Slow progression \\
\hline SCA40 & CCDC88C & $14 q 32.12$ & MM & WNT signaling & Reported in one patient. \\
\hline SCA41 & TRPC3 & $4 q 27$ & MM & $\begin{array}{l}\text { Regulations MP, } \\
\text { Ca signalling }\end{array}$ & Reported in one family. \\
\hline
\end{tabular}

Table 1. Genes, loci, gene function and distinguishing features of autosomal dominant hereditary ataxias. Classified according to the Harding classification (1982). Exp Expansion. FS Frameshift. MM Missense mutation. 


\begin{tabular}{|c|c|c|c|c|c|}
\hline Disorder & Gene & Loci & Mutation & Function & Comments \\
\hline Friedreich's ataxia & FXN & $9 q 13$ & $\begin{array}{l}\text { GAA repeat, } \\
\text { Deletion }\end{array}$ & $\begin{array}{l}\text { Mitochondria iron } \\
\text { transport and } \\
\text { respiration }\end{array}$ & $\begin{array}{l}\text { Neuropathy, insulin resistance, } \\
\text { cardiomyopathy, scoliosis, visual } \\
\text { and hearing impairment }\end{array}$ \\
\hline Cayman ataxia & ATCAY & $19 \mathrm{p} 13.3$ & MM & $\begin{array}{l}\text { Neural tissue } \\
\text { development }\end{array}$ & $\begin{array}{l}\text { Psychomotor retardation; } \\
\text { frequent in Cayman population }\end{array}$ \\
\hline Refsum's disease & $\begin{array}{l}\text { Pex7, } \\
\text { PHYH }\end{array}$ & $\begin{array}{l}6 \mathrm{q} 23.3, \\
10 \mathrm{p} 13\end{array}$ & MM, FS & Fatty acid oxidation & $\begin{array}{l}\text { Neuropathy, ichthyosis, } \\
\text { retinopathy }\end{array}$ \\
\hline Abetalipoproteinaemia & MTTP & $4 q 23$ & NM, MS, FS & Lipoprotein assembly & $\begin{array}{l}\text { Fat malabsorption, } \\
\text { acanthocytosis, neuropathy, } \\
\text { spasticity }\end{array}$ \\
\hline $\begin{array}{l}\text { Autosomal recessive } \\
\text { spastic ataxia of } \\
\text { Charlevoix-Saguenay }\end{array}$ & SACS & $13 w 12$ & MM, FS & $\begin{array}{l}\text { Regulates ataxia } \\
\text { proteins }\end{array}$ & $\begin{array}{l}\text { Spastic paraparesis; } \\
\text { OCT: hypertrophy of myelinated } \\
\text { fibres }\end{array}$ \\
\hline Ataxia telangiectasia & ATM & $11 q 22.3$ & $\begin{array}{l}\text { MM, NM, } \\
\text { deletion }\end{array}$ & Phosphorylation & $\begin{array}{l}\text { Telangiectasias, cancer, } \\
\text { immunodeficiency; raised } \alpha \text { - } \\
\text { fetoprotein }\end{array}$ \\
\hline $\begin{array}{l}\text { Ataxia telangiectasia- } \\
\text { like disorder }\end{array}$ & MRE11 & $11 q 21$ & MM, NM & $\begin{array}{l}\text { DNA double-strand } \\
\text { break repair }\end{array}$ & $\begin{array}{l}\text { Mimics ataxia telangiectasia; no } \\
\text { ocular telangiectasias }\end{array}$ \\
\hline $\begin{array}{l}\text { Ataxia with } \\
\text { oculomotor apraxia } \\
\text { type } 1\end{array}$ & APTX & $9 p 21.1$ & MM, LOF & $\begin{array}{l}\text { Single-stranded DNA } \\
\text { repair }\end{array}$ & $\begin{array}{l}\text { Oculomotor apraxia, chorea, } \\
\text { dystonia, neuropathy }\end{array}$ \\
\hline $\begin{array}{l}\text { Ataxia with } \\
\text { oculomotor apraxia } \\
\text { type } 2\end{array}$ & SETX & $9 q 34.13$ & MM & $\begin{array}{l}\text { DNA and RNA } \\
\text { processing }\end{array}$ & $\begin{array}{l}\text { Oculomotor apraxia, chorea, } \\
\text { dystonia, neuropathy }\end{array}$ \\
\hline $\begin{array}{l}\text { Ataxia with } \\
\text { oculomotor apraxia } \\
\text { type } 3\end{array}$ & PIK3R5 & $17 p 13.1$ & MM & Phosphorylation & Oculomotor apraxia, neuropathy \\
\hline $\begin{array}{l}\text { Cerebrotendinous } \\
\text { xanthomatosis }\end{array}$ & CYP27A1 & $2 q 35$ & MM & Oxidation & $\begin{array}{l}\text { Xanthomas, spasticity, } \\
\text { neuropathy, intellectual } \\
\text { disability, cataracts }\end{array}$ \\
\hline $\begin{array}{l}\text { Marinesco-Sjogren } \\
\text { syndrome }\end{array}$ & SIL1 & $5 q 31.2$ & LOF & $\begin{array}{l}\text { Nucleotide exchange } \\
\text { factor }\end{array}$ & $\begin{array}{l}\text { Hypotonia, intellectual disability, } \\
\text { early-onset cataract }\end{array}$ \\
\hline SANDO/MIRAS & POLG1 & $15 q 26.1$ & MM & $\begin{array}{l}\text { Mitochondrial DNA } \\
\text { polymerase }\end{array}$ & $\begin{array}{l}\text { Myoclonus, dysarthria, } \\
\text { ophthalmalgia }\end{array}$ \\
\hline $\begin{array}{l}\text { Autosomal recessive } \\
\text { ataxia type } 1\end{array}$ & SYNE1 & $6 q 25.2$ & Splice site & $\begin{array}{l}\text { Nuclear membrane } \\
\text { localisation }\end{array}$ & $\begin{array}{l}\text { Cerebellar atrophy, lack of } \\
\text { neuropathy }\end{array}$ \\
\hline $\begin{array}{l}\text { Autosomal recessive } \\
\text { ataxia type } 2\end{array}$ & ADCK3 & $1 q 42.13$ & Splice site & $\begin{array}{l}\text { Electron transfer, } \\
\text { respiratory chain }\end{array}$ & $\begin{array}{l}\text { Mental disability, epilepsy } \\
\text { myoclonus, exercise intolerance }\end{array}$ \\
\hline $\begin{array}{l}\text { Autosomal recessive } \\
\text { ataxia type } 3\end{array}$ & ANO10 & $\begin{array}{l}3 p 22.1- \\
\text { p21.33 }\end{array}$ & LOF & $\begin{array}{l}\text { Calcium-activated } \\
\text { chloride channels }\end{array}$ & Pure ataxia \\
\hline
\end{tabular}




\begin{tabular}{|c|c|c|c|c|c|}
\hline Late onset Tay-Sachs & HEXA & $15 q 23$ & MM, LOF & $\begin{array}{l}\text { Ganglioside } \\
\text { degradation }\end{array}$ & $\begin{array}{l}\text { Motor neuron involvement, } \\
\text { psychiatric features }\end{array}$ \\
\hline $\begin{array}{l}\text { Ataxia with Vitamin E } \\
\text { deficiency }\end{array}$ & TTPA & $8 q 12.3$ & FS & $\begin{array}{l}\text { Regulating vitamin } \mathrm{E} \\
\text { levels }\end{array}$ & $\begin{array}{l}\text { Mimics Friedreich's ataxia, } \\
\text { decreased Vitamin E, head } \\
\text { tremor }\end{array}$ \\
\hline Cockayne Syndrome & ERCC8 & $5 q 12.2$ & NM, MM & Signal transduction & $\begin{array}{l}\text { Microcephaly, growth } \\
\text { retardation, photosensitivity, } \\
\text { progeria }\end{array}$ \\
\hline Niemann-Pick type C1 & NPC1 & $18 q 11.2$ & $\mathrm{MM}, \mathrm{FS}$ & $\begin{array}{l}\text { Cholesterol } \\
\text { trafficking }\end{array}$ & $\begin{array}{l}\text { Vertical supranuclear palsy, } \\
\text { splenomegaly, dystonia, } \\
\text { cognitive disability }\end{array}$ \\
\hline $\begin{array}{l}\text { Fragile } \mathrm{X} \text {-associated } \\
\text { tremor/ataxia } \\
\text { syndrome }\end{array}$ & FMR1 & Xq27.3 & $\begin{array}{l}\text { CGG repeat } \\
\text { (5' UTR) }\end{array}$ & RNA binding & $\begin{array}{l}\text { Late-onset, intention tremor, } \\
\text { cognitive problems }\end{array}$ \\
\hline $\begin{array}{l}\text { Spinocerebellar ataxia } \\
\text { with axonal } \\
\text { neuropathy }\end{array}$ & TDP1 & $14 q 32.11$ & MM & $\begin{array}{l}\text { Repairing stalled } \\
\text { topoisomerase I-DNA } \\
\text { complexes }\end{array}$ & Peripheral neuropathy \\
\hline $\begin{array}{l}\text { Infantile-onset } \\
\text { spinocerebellar ataxia }\end{array}$ & C10orf2 & $10 q 24.31$ & MM & $\begin{array}{l}\text { mtDNA-specific } \\
\text { helicase }\end{array}$ & $\begin{array}{l}\text { Atheosis, muscle hypotonia, } \\
\text { optic atrophy, primary } \\
\text { hypogonadism in females }\end{array}$ \\
\hline $\begin{array}{l}\text { Dilated } \\
\text { cardiomyopathy with } \\
\text { ataxia }\end{array}$ & DNAJC19 & $3 q 26.33$ & Splice site & $\begin{array}{l}\text { ATP-dependent } \\
\text { transport }\end{array}$ & Early-onset cardiomyopathy \\
\hline SeSAME syndrome & KCNJ10 & $1 q 23.2$ & LOF, MM & Potassium buffering & $\begin{array}{l}\text { Seizures, sensorineural } \\
\text { deafness, ataxia, mental } \\
\text { retardation and electrolyte } \\
\text { imbalance }\end{array}$ \\
\hline $\begin{array}{l}\text { Cerebellar ataxia, } \\
\text { mental retardation, } \\
\text { and disequilibrium } \\
\text { syndrome } 3\end{array}$ & CA8 & $8 q 12.1$ & MM & Gene transcription & Cognitive impairment \\
\hline PHARC & ABHD12 & 20p11.21 & LOF & $\begin{array}{l}\text { Hydrolysis of lipid } \\
\text { transmitters }\end{array}$ & $\begin{array}{l}\text { Polyneuropathy, hearing loss, } \\
\text { ataxia, retinitis pigmentosa and } \\
\text { cataract }\end{array}$ \\
\hline $\begin{array}{l}\text { Autosomal recessive } \\
\text { spinocerebellar ataxia } \\
15\end{array}$ & KIAA0226 & $3 q 29$ & FS & $\begin{array}{l}\text { Vesicular trafficking, } \\
\text { endosome } \\
\text { maturation }\end{array}$ & Epilepsy \\
\hline Spastic ataxia type 4 & MTPAP & 10p11.23 & $\mathrm{MM}$ & mRNA degradation & Spasticity \\
\hline $\begin{array}{l}\text { Posterior column } \\
\text { ataxia with retinitis } \\
\text { pigmentosa }\end{array}$ & FLVCR1 & $1 q 32.3$ & MM & Heme transporter & $\begin{array}{l}\text { Impairment of vison and } \\
\text { proprioception }\end{array}$ \\
\hline $\begin{array}{l}\text { Spinocerebellar ataxia } \\
\text { type } 11\end{array}$ & TTBK2 & $15 q 15.2$ & NM & Phosphorylation & $\begin{array}{l}\text { Occasionally pyramidal } \\
\text { involvement and peripheral } \\
\text { neuropathy }\end{array}$ \\
\hline $\begin{array}{l}\text { Cerebellar ataxia, } \\
\text { mental retardation }\end{array}$ & WDR81 & $17 p 13.3$ & MM & $\begin{array}{l}\text { Endolysosomal } \\
\text { trafficking }\end{array}$ & Cognitive impairment \\
\hline
\end{tabular}


and disequilibrium

syndrome 2

Autosomal recessive

spinocerebellar ataxia

14

Autosomal recessive

spinocerebellar ataxia 13

Spastic ataxia type 3

Duplicationdeletion

Autosomal recessive

GRID2

4q22.1- Deletion

$\mathrm{q} 22.2$

18

Autosomal recessive

spinocerebellar ataxia

16

Autosomal recessive

spinocerebellar ataxia

7

Cerebellar ataxia, mental retardation and disequilibrium syndrome 4

Autosomal recessive spinocerebellar ataxia 12

Autosomal recessive spinocerebellar ataxia 20

Autosomal recessive spinocerebellar ataxia 23

Autosomal recessive spinocerebellar ataxia 17

Spastic ataxia type 2

Ataxia with oculomotor apraxia type 4

Autosomal recessive spinocerebellar ataxia 2

STUB1 16p13.3 MM

TPP1

8q12.3 Splice site, MM

ATP8A2 13q12.13 MM

WWOX

16q23.1- MM $\mathrm{q} 23.2$

SNX14

$6 q 14.3$

TM

TDP2

6p22.3 Splice site

CWF19L1 10q24.31 Stop codon (FS)

KIF2C

$1 \mathrm{p} 34.1$

Deletionduplication

PNKP

PMPCA

$9 q 34.3$

MM
SPTBN2 11q13.2 MM Glutamate signaling

19q13.33 LOF regulation

Glutamatergic neurotransmission

Mitochondrial

Synapse organisation

Delayed psychomotor development, retinopathy

E3 ubiquitin ligase

Occasionally hypogonadism

Regulating vitamin $\mathrm{E}$ levels

Lipid flipping

Cognitive impairment

Apoptosis

Intracellular

trafficking

DNA repair

Microtubuledependent molecular motor

Early-onset ataxia, psychomotor developmental delay

Delayed psychomotor development, mental retardation

Spasticity, Leukoencephalopathy

Developmental delay

Epilepsy, delayed psychomotor development, mental retardation

Delayed psychomotor development

Delayed psychomotor development, seizures

Developmental delay

Spasticity

DNA repair

Oculomotor apraxia, microcephaly, seizures

Cognitive impairment, dystonia, spasticity 


$\begin{array}{llllll}\begin{array}{l}\text { Autosomal recessive } \\ \text { spinocerebellar ataxia }\end{array} & \text { UBA5 } & 3 q 22.1 & \text { MM } & \begin{array}{l}\text { Activates ubiquitin- } \\ \text { fold modifier } 1\end{array} & \text { Early-onset cataract } \\ \begin{array}{l}\text { Autosomal recessive } \\ \begin{array}{l}\text { spinocerebellar ataxia } \\ 22\end{array}\end{array} & \text { VWA3B } & 2 q 11.2 & \text { MM } & \begin{array}{l}\text { Transcription/DNA } \\ \text { repair }\end{array} & \text { Spasticity, intellectual disabilty } \\ \end{array}$

Table 1. Genes, loci, gene function and distinguishing features of autosomal recessive hereditary ataxias. DR duplication rearrangement. FS frame shift. NM nonsense mutation. MM missense mutation. LOF loss of function. TM truncation mutation. 